\title{
Synthesis and leishmanicidal evaluation of sulfanyl and sulfonyl-tethered functionalized benzoate derivatives featuring a nitroimidazole moiety
}

Miguel Rodríguez ${ }^{1}$ | Joyce Gutiérrez ${ }^{1}$ | José Domínguez ${ }^{1}$ | Philippe A. Peixoto ${ }^{2}$ | Alexis Fernández ${ }^{3}$ | Noris Rodríguez ${ }^{3}$ | Denis Deffieux ${ }^{2}$ | Luis Rojas ${ }^{4}$ | Stéphane Quideau $^{2}$ | Laurent Pouységu ${ }^{2}$ | Jaime Charris ${ }^{1}$

${ }^{1}$ Laboratorio de Síntesis Orgánica, Facultad de Farmacia, Universidad Central de Venezuela, Apartado 47206, Los Chaguaramos, 1041-A Caracas, Venezuela

${ }^{2}$ Univ. Bordeaux, ISM (CNRS-UMR 5255), 351 cours de la Libération, 33405 Talence Cedex, France

${ }^{3}$ Instituto de Biomedicina, Facultad de Medicina, Universidad Central de Venezuela, Apartado 4043, Caracas 1010A, Venezuela

${ }^{4}$ Universidad de Los Andes, Laboratorio de Productos Naturales, Facultad de Farmacia y Bioanálisis, 5101 Mérida, Venezuela

\section{Correspondence}

Laurent Pouységu, Univ. Bordeaux, ISM (CNRS-UMR 5255), 351 cours de la Libération, 33405 Talence Cedex, France.

Email: laurent.pouysegu@u-bordeaux.fr

Jaime Charris, Laboratorio de Síntesis Orgánica, Facultad de Farmacia, Universidad Central de Venezuela, Apartado 47206, Los Chaguaramos, 1041-A Caracas, Venezuela.

Email: jaime.charris@ucv.ve

\section{KEYWORDS}

Synthesis, Nitroimidazole, Antiproliferative agents 


\section{Abstract}

Herein is described the synthesis of a series of new nitroimidazole-containing derivatives by coupling of 2-[2-(2-methyl-5-nitro-1H-imidazol-1-yl)ethylthio]ethanol with diversely substituted benzoic acids. Upon treatment with $m$-CPBA, twelve of these sulfanyl compounds were further oxidized into their sulfonyl analogues. All the twenty six synthetic compounds were examined for in vitro activity against $L$. (V.) braziliensis and L. (L.) mexicana, and some of them displayed efficient antileishmanial activity. Among the compounds tested, the catecholic derivative 2\{[2-(2-methyl-5-nitro-1H-imidazol-1-yl)ethyl]sulfanyl\}ethyl 3,4-dihydroxybenzoate $\left(9 \mathrm{a}, \mathrm{LC}_{50}=13\right.$ and $11 \mu \mathrm{M}$, respectively) and the pyrogallolic derivative 2-\{[2-(2methyl-5-nitro-1H-imidazol-1-yl)ethyl]sulfanyl\}ethyl 3,4,5-trihydroxybenzoate (9b, $\mathrm{LC}_{50}=4$ and $1 \mu \mathrm{M}$, respectively) were the most active against the two Leishmania strains.

\section{1 | Introduction}

Leishmaniasis is an infectious disease caused by protozoa of the genus Leishmania. A recent review shows that over 98 countries and territories are endemic for leishmaniasis transmission, with an overall prevalence of 12 million cases. Over 20 Leishmania species known to be infective to humans are transmitted by the bite of infected female phlebotomine sandflies, thus giving three main types of leishmaniasis: visceral (VL), cutaneous (CL), and mucocutaneous (MCL). It is estimated that approximately 0.2 to 0.4 million of new $V L$ cases and 0.7 to 1.2 million of new CL cases occur each year. These diseases are responsible annually for approximately 20.000 to 40.000 deaths. ${ }^{[1]}$ Leishmaniasis control relies on chemotheraphy, since an effective vaccine is not available in the market, but available drugs are limited. The recommended first-line therapies include pentavalent antimony compounds, such as sodium stibogluconate and meglutamine antimoniate, although these drugs present several disadvantages, such as toxicity, high costs, prolonged treatment, and parenteral or intralesional routes of administration. The second-line treatments include pentamidine and amphotericin B, but their use is limited because of toxicity and cost, even though 
lipid and liposomal formulations of amphotericin B have been developed to reduce this toxicity. Recently, the oral administration of miltefosine has been used for the treatment of $\mathrm{VL}$ in some countries, but despite its great efficacy, miltefosine is not free either from toxicity as it shows teratogenic potential. ${ }^{[2-4]}$ Several compounds that show leishmanicidal activity are currently in different stages of development. Among them, a few classes of compounds, such as the 8-aminoquinolinic sitamaquine ${ }^{[5]}$ the 7 -aminoimidazoquinolinic imiquimod, ${ }^{[6]}$ the triazolic posaconazole,$^{[7]}$ the 5 -nitroimidazole fexinidazole ${ }^{[8]}$ as well as/some natural product derivatives, such as licochalcone $A,{ }^{[9]}$ have been revealed as potential new drugs for antileishmania therapy. The synthesis of several molecules showing leishmanicidal activity and that of new lead compounds, such as $\beta$-carboline alkaloids, ${ }^{[10]}$ piperoylaminoacid conjugates, ${ }^{[11]}$ heteroretinoidbis(benzylidene)ketones, ${ }^{[12]}$ and bispyridinium cyclophanes, have also been described. ${ }^{[13]}$ In addition, the drawbacks associated with the currently available treatments have led to the development of new strategies aiming at leishmaniasis control. In this context, special attention has been given to nitroaromatic scaffolds, as such compounds are used to treat a wide variety of diseases, including Parkinson's disease, angina, and insomnia, ${ }^{[14-16]}$ as well as several infections caused either by bacteria or by a range of pathogenic protozoan parasites as reported over the past 60 years. ${ }^{[17-18]}$ For instance, metronidazole, tinidazole, ornidazole, benznidazole, fexinidazole and nifurtimox are the recommended drugs for treatment of protozoan infections. ${ }^{[19-23]}$ In biological systems, nitro groups can undergo enzymatic reduction by reaction with nitroreductase (NTR) enzymes. The resulting damages to the cells mainly occur in two ways, either by oxidative stress or through the formation of adducts between a protein or non-protein thiol and some intermediate metabolites. ${ }^{[2]}$ In the search for more effective alternatives to the currently used antileishmanial drugs, we synthesized a set of novel metronidazole analogues featuring an heterocyclic and basic 5-nitroimidazole head linked to a substituted benzoic acid through a dialkyl sulfur chain, and further tested them in vitro against strains of $L$. (V.) braziliensis (MHOM/BR/75/M2903) and $L$. (L.) mexicana (MHOM/BZ/82/Bel21). The choice of this sulfur-containing 
spacer was related to some reported work ${ }^{[25]}$ and to our previous successful experience with 7-chloroquinolin-4-ylthio derivatives, which exhibited an excellent in vitro antiplasmodial activity against chloroquine sensitive strain of $P$. berghei, and good in vivo efficacy in murine models of malaria, together with an excellent in vitro and in vivo antitumoral activity against prostate cancer. ${ }^{[26]}$ Our interest in metronidazole analogues as an alternative to antiprotozoan treatments also lies in the fact that side chains attached to position 1 of the imidazole nucleus provide an interesting opportunity to quickly carry out various modifications.

\section{2 | RESULTS AND DISCUSSION}

\subsection{Chemistry}

Our synthesis work began from metronidazole ${ }^{\circledR} \mathbf{1}$, whose primary alcohol was substituted by either a chlorine atom or a mesyl group. Following known procedures, ${ }^{[27,28]}$ upon reaction with thionyl chloride, 1 was converted into the corresponding hydrochloride salt, which was then treated with water and $\mathrm{Et}_{3} \mathrm{~N}$ until $\mathrm{pH} \mathrm{11,} \mathrm{to} \mathrm{obtain} \mathrm{the} \mathrm{1-(2-chloroethyl)-2-methyl-5-nitroimidazole} \mathrm{(2)} \mathrm{with} \mathrm{a} \mathrm{yield} \mathrm{of}$ $96 \%$ (Scheme 1). Alternatively, treatment of 1 with mesyl chloride and $\mathrm{Et}_{3} \mathrm{~N}$ in dichloromethane $\left(\mathrm{CH}_{2} \mathrm{Cl}_{2}\right)$, at room temperature, afforded the O-mesylated metronidazole (3) in a very good yield of $96 \%$. Subsequent nucleophilic substitution of $\mathbf{3}$, using sodium iodide in refluxing acetone, gave the iodinated compound $\mathbf{4}$ in $96 \%$ yield. ${ }^{[27,28]}$ The nucleophilic substitution of 2 and $\mathbf{4}$ with 2-mercaptoethanol furnished the thioether-linked metronidazole analogue 5. This compound was obtained in good yield (61\%) when the reaction was carried out with 2 as the starting material, but the modified experimental protocol using 4 turned out to be more efficient and allowed us to prepare 5 in an even better yield $(77 \%)$. The final compounds $\mathbf{7 a - I}$ were synthesized via a coupling reaction between $\mathbf{5}$ and a series of benzoic acids, in the presence of $N$-(3-dimethylaminopropyl)- $N$ 'ethylcarbodiimide hydrochloride (EDCI) and 4-(dimethylamino)-pyridine (DMAP) in $\mathrm{CH}_{2} \mathrm{Cl}_{2}$. The title compounds were isolated in good-to-excellent (60-94\%) yields after purification by recrystallization or by column chromatography (Scheme 1). 
In addition, two polyhydroxy aromatic derivatives $9 a$ and $\mathbf{9 b}$ were prepared respectively from commercially available protocatechuic acid and gallic acid, whose aromatic hydroxyl functions were previously protected with tertbutyldimethylsilyl groups ${ }^{[29]}$ After coupling $\mathbf{8 a}$ and $\mathbf{8} \mathbf{b}$ with $\mathbf{5}$, the protecting groups were removed efficiently upon treatment with tetra- $n$-butylammonium fluoride (TBAF), in the presence of acetic acid, to afford compounds $\mathbf{9 a}$ and $\mathbf{9 b}$ with very good isolated yields of $95 \%$ and $73 \%$, respectively (Scheme 1).

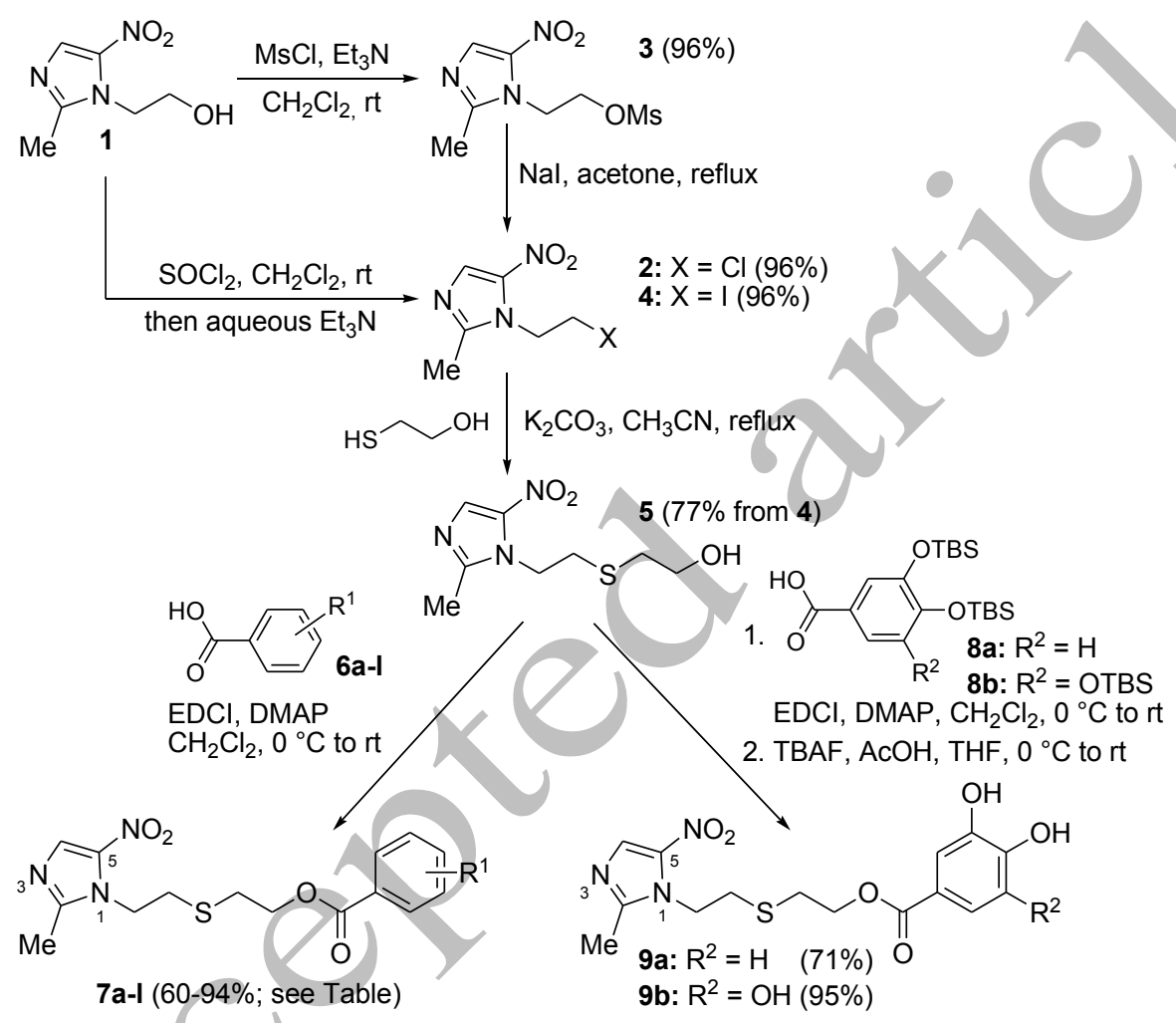

SCHEME 1 Synthesis of the 2-\{[2-(1H-imidazol-1-yl)ethyl]sulfanyl\}ethyl benzoate derivatives $\mathbf{7 a - I}$ and $\mathbf{9 a}$,b.

\begin{tabular}{|c|c|c|c|c|c|}
\hline No & $\mathrm{R}^{1}$ & Yield (\%) & No & $\mathrm{R}^{1}$ & Yield (\%) \\
\hline $7 a$ & 2 -OMe & 74 & $7 \mathrm{~g}$ & $3,4,5-\mathrm{OMe}$ & 79 \\
\hline $7 b$ & 4-OMe & 94 & $7 \mathrm{~h}$ & 4-OMe-3- $\mathrm{NO}_{2}$ & 84 \\
\hline $7 c$ & 2,3-OMe & 79 & $7 \mathbf{i}$ & 3,5-Me & 87 \\
\hline $7 d$ & 2,4-OMe & 75 & $7 \mathbf{j}$ & 4- $\left(\mathrm{CH}_{3}\right)_{3} \mathrm{C}$ & 75 \\
\hline $7 e$ & 2,5-OMe & 65 & $7 k$ & 5-Me-2- $\mathrm{NO}_{2}$ & 88 \\
\hline $7 f$ & 2,4,5-OMe & 60 & 71 & $4-\mathrm{CF}_{3}$ & 72 \\
\hline
\end{tabular}


Further $m$-CPBA-mediated oxidation of compounds $7 \mathrm{a}-\mathrm{I}$ gave a rapid and efficient (61-93\% yield) access to the corresponding sulfonyl analogues 10a-I (Scheme 2). The chemical structures of all synthesized compounds were confirmed on the basis of their NMR and IR spectral data, and their purity was ascertained by microanalysis. In ${ }^{1} \mathrm{H}$ NMR spectra, the signal of the respective protons of the compounds were checked on the basis of their chemical shifts, multiplicities, and coupling constants.

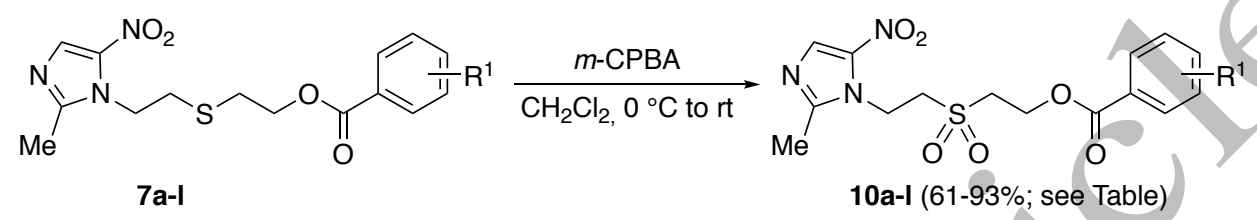

SCHEME 2 Synthesis of the 2-\{[2-(1H-imidazol-1-yl)ethyl]-sulfonyl\}ethyl benzoate derivatives 10a-I.

\begin{tabular}{cccccc}
\hline No & $\mathbf{R}^{1}$ & Yield (\%) & No & $\mathbf{R}^{1}$ & Yield (\%) \\
\hline $\mathbf{1 0 a}$ & $2-\mathrm{OMe}$ & 80 & $\mathbf{1 0 g}$ & $3,4,5-\mathrm{OMe}$ & 77 \\
$\mathbf{1 0 b}$ & $4-\mathrm{OMe}$ & 76 & $\mathbf{1 0 h}$ & $4-\mathrm{OMe}-3-\mathrm{NO}_{2}$ & 77 \\
$\mathbf{1 0 c}$ & $2,3-\mathrm{OMe}$ & 75 & $\mathbf{1 0 i}$ & $3,5-\mathrm{Me}$ & 80 \\
$\mathbf{1 0 d}$ & $2,4-\mathrm{OMe}$ & 92 & $\mathbf{1 0 j}$ & $4-\left(\mathrm{CH}_{3}\right)_{3} \mathrm{C}$ & 93 \\
$\mathbf{1 0 e}$ & $2,5-\mathrm{OMe}$ & 86 & $\mathbf{1 0 k}$ & $5-{\mathrm{Me}-2-\mathrm{NO}_{2}}_{2}$ & 77 \\
$\mathbf{1 0 f}$ & $2,4,5-\mathrm{OMe}$ & 61 & $\mathbf{1 0 l}$ & 4-CF & 69 \\
\hline
\end{tabular}

All compounds showed a single signal ranging from $\delta \mathrm{H} 7.9$ to $8.5 \mathrm{ppm}$, which was assigned to the $\mathrm{H}-4$ of the imidazole ring. The aliphatic signals expected at upfield shifts were found from $\delta \mathrm{H} 2.9$ to $4.5 \mathrm{ppm}$. The aromatic region of the ${ }^{1} \mathrm{H}$ NMR spectra featured signal patterns ranging from $\delta \mathrm{H} 6.5$ to $8.0 \mathrm{ppm}$, and were characteristic of the substitution pattern of each aromatic ring. The ${ }^{13} \mathrm{C} N M R$ spectra showed characteristic signals of the 5-nitroimidazole core, with one signal resonating at $\delta C 140-165 \mathrm{ppm}$, which was attributed to $C-5$, as well as two signals observed in the $\delta C 138-152$ and $124-140$ ppm regions, which were assigned to C2 and C-4, respectively. For the carboxyl group, another characteristic signal was observed further downfield around $\delta \mathrm{C}$ 165-166 ppm. 


\section{2 | Biological evaluation}

The synthesized compounds were evaluated for their antileishmanial activity against in vitro forms of $L$. (V.) braziliensis and L. (L.) mexicana (promastigotes) strains. The main results are summarized in Table 1 , in which the data are reported as mean $\pm \mathrm{SD}$ after a statistical analysis by one-way ANOVA. The $\mathrm{LC}_{50}$ values were calculated using sigmoid dose-response curves. In comparison with metronidazole $^{\circledR}\left(1, L^{2} C_{50}>1 \mathrm{mM}\right)$, compounds $7 \mathrm{~b}, 7 \mathrm{~d}, 7 \mathrm{e}, 9 \mathrm{a}$ and $9 \mathrm{~b}$ showed higher activity against promastigotes of $L$. (V.) braziliensis ( $\mathrm{LC}_{50}$ ranging from 4 to $32 \mu \mathrm{M}$ ), but only $9 \mathrm{a}$ and $9 \mathrm{~b}$ were active against the glucantime-resistant promastigotes of $L$. (L.) mexicana ( $\mathrm{LC}_{50}$ of 11 and $1 \mu \mathrm{M}$, respectively). When compounds 7a-I were oxidized into the corresponding sulfones $10 \mathrm{a}-\mathrm{I}$, compounds $10 \mathrm{~g}, 10 \mathrm{~h}$ and $10 \mathrm{i}$ were found to be the most active of this group of molecules against the $L$. (V.) braziliensis promastigotes $\left(\mathrm{LC}_{50}\right.$ ranging from 23 to $\left.134 \mu \mathrm{M}\right)$, but these three sulfonyl analogues revealed weakly active against the L. (L.) mexicana ones (see Table 1).

Compounds $\mathbf{7 h}, \mathbf{7 j}, \mathbf{7 l}, \mathbf{1 0 k}$ and $\mathbf{1 0 l}$ showed weak antileishmanial activity, whilst compounds $5,7 \mathrm{a}, 7 \mathrm{c}, \mathbf{7 f}, \mathbf{7 i}, \mathbf{7 k}, \mathbf{1 0 d}, 10 \mathrm{e}$ and $10 \mathrm{f}$ exhibited almost no activity against $L$. (V.) braziliensis and $L$. (L.) mexicana (with the exception of 10 on this last strain). It is evident from these results that compounds featuring aromatic hydroxyl and methoxy groups are the most active ones, and that their added hydrophilic character likely plays an essential role in producing an antileishmanial effect, with hydroxy groups being more effective than methoxy substituents. An hypothetical explanation could also be proposed based on oxidative dehydrogenation of the catechol- and pyrogallol-bearing phenols $9 \mathrm{a}$ and $\mathbf{9 b}$ into ortho-quinones (i.e., 11a and 11b, Scheme 3), as such electrophilic entities can be engaged in covalently trapping proteins via their nucleophilic amino acid residue side chains, hence possibly causing inactivation of sensitive enzymes. ${ }^{[0,31]}$ Introduction of electron-withdrawing or hydrophobic groups, such as $\mathrm{NO}_{2}, \mathrm{CF}_{3}, \mathrm{CH}_{3}$ or $\mathrm{C}\left(\mathrm{CH}_{3}\right)_{3}$, leads to an almost inactive compounds. It is worthy to mention that a sulfanyl group (i.e., reduced sulfur atom) was more effective than a sulfonyl group (i.e., oxidized sulfur atom). 
TABLE 1 Preliminary evaluation of the in vitro antileishmanial activity of compounds $\mathbf{7 a - I}, \mathbf{9 a}, \mathbf{b}$ and $10 \mathrm{~d}-\mathrm{I}$ on the L. braziliensis and L. mexicana promastigotes growth

\begin{tabular}{|c|c|c|c|}
\hline \multirow[t]{2}{*}{$\mathbf{N}^{\circ}$} & \multirow[t]{2}{*}{$\mathbf{R}$} & $\mathrm{LC}_{50}(\mathrm{mM})$ & $\mathrm{LC}_{50}(\mathrm{mM})$ \\
\hline & & L. braziliensis & L. mexicana \\
\hline 5 & - & $0.95 \pm 0.032$ & $2.25 \pm 0.054$ \\
\hline $7 a$ & $2-\mathrm{OCH}_{3}$ & $0.417 \pm 0.021$ & $>1$ \\
\hline $7 b$ & $4-\mathrm{OCH}_{3}$ & $0.009 \pm 0.002$ & $0.215 \pm 0.034$ \\
\hline $7 c$ & $2,3-\mathrm{OCH}_{3}$ & $0.432 \pm .0 .018$ & $0.734 \pm 0.032$ \\
\hline $7 d$ & $2,4-\mathrm{OCH}_{3}$ & $0.009 \pm 0.003$ & $0.229 \pm 0.05$ \\
\hline $7 e$ & $2,5-\mathrm{OCH}_{3}$ & $0.032 \pm 0.024$ & $0.706 \pm 0.021$ \\
\hline $7 f$ & $2,4,5-\mathrm{OCH}_{3}$ & $0.908 \pm 0.081$ & $0.632 \pm 0.355$ \\
\hline $7 g$ & $3,4,5-\mathrm{OCH}_{3}$ & $0.464 \pm 0.003$ & $0.352 \pm 0.089$ \\
\hline $7 \mathrm{~h}$ & $3-\mathrm{NO}_{2}-4-\mathrm{OCH}_{3}$ & $0.253 \pm 0.031$ & $0.168 \pm 0.035$ \\
\hline $7 \mathbf{i}$ & $3,5-\mathrm{CH}_{3}$ & $0.585 \pm 0.015$ & $0.456 \pm 0.017$ \\
\hline $7 \mathbf{j}$ & $4-\mathrm{C}\left(\mathrm{CH}_{3}\right)_{3}$ & $0.129 \pm 0.017$ & $0.188 \pm 0.016$ \\
\hline $7 k$ & $2-\mathrm{NO}_{2}-5-\mathrm{CH}_{3}$ & $0.442 \pm 0.012$ & $0.479 \pm 0.002$ \\
\hline 7I & $4-\mathrm{CF}_{3}$ & $0.356 \pm 0.003$ & $0.098 \pm 0.005$ \\
\hline $9 a$ & $3,4-\mathrm{OH}$ & $0.013 \pm 0.001$ & $0.011 \pm 0.002$ \\
\hline $9 b$ & $3,4,5-\mathrm{OH}$ & $0.004 \pm 0.002$ & $0.001 \pm 0.001$ \\
\hline $10 d$ & $2,4-\mathrm{OCH}_{3}$ & $0.411 \pm 0.042$ & $0.420 \pm 0.004$ \\
\hline $10 e$ & $2,5-\mathrm{OCH}_{3}$ & & $>1$ \\
\hline $10 f$ & $2,4,5-\mathrm{OCH}_{3}$ & $0.981 \pm 0.049$ & $0.037 \pm 0.004$ \\
\hline $10 \mathrm{~g}$ & $3,4,5-\mathrm{OCH}_{3}$ & $0.023 \pm 0.019$ & $>1$ \\
\hline $10 \mathrm{~h}$ & $3-\mathrm{NO}_{2}-4-\mathrm{OCH}_{3}$ & $0.134 \pm 0.006$ & $0.343 \pm 0.075$ \\
\hline $10 i$ & $3,5-\mathrm{CH}_{3}$ & $0.120 \pm 0.029$ & $0.977 \pm 0.180$ \\
\hline $10 j$ & $4-\mathrm{C}\left(\mathrm{CH}_{3}\right)_{3}$ & $0.664 \pm 0.019$ & $0.497 \pm 0.011$ \\
\hline $10 k$ & $2-\mathrm{NO}_{2}-5-\mathrm{CH}_{3}$ & $0.303 \pm 0.012$ & $0.904 \pm 0.045$ \\
\hline 10I & $4-\mathrm{CF}_{3}$ & $0.464 \pm 0.076$ & $0.176 \pm 0.025$ \\
\hline
\end{tabular}

LC $_{50}$ for compounds 5-9b: S; 10d-10I: $\mathrm{SO}_{2}$. Untreated control was used as control (-).<smiles>[R]c1cc(C(=O)OCCSCCn2c(C)nnc2C)cc(O)c1O</smiles><smiles>[R]C1=CC(C(=O)OCCSCCn2c([N+](=O)[O-])cnc2C)=CC(=O)C1=O</smiles>

SCHEME 3 Oxidation of catechol- and pyrogallol-type phenols $9 \mathrm{a}$ and $\mathbf{9 b}$ into reactive ortho-quinone species $11 \mathrm{a}$ and $\mathbf{1 1 b}$.

\section{3 | CONCLUSION}


A series of novel metronidazole ${ }^{\circledR}$ derivatives has been synthesized and tested as antileishmanial agents against promastigotes of $L$. (V.) braziliensis and $L$. (L.) mexicana. Among the tested compounds, the catecholic and pyrogallolic benzoate derivatives $\mathbf{9 a}$ and $\mathbf{9 b}$ have shown a significant in vitro activity superior to that of the parent drug, which may result from several independent or combined causes. The improved amphiphilic character brought by the di/trihydroxylated benzoate function may lead to an increase of the concentration of the compound inside the parasite form, thus increasing the interactions with leishmanial functional proteins. Furthermore, the dehydrogenation of their cathecol or pyrogallol moieties into electrophilic quinones could mediate covalent modifications of these proteins. Alternatively, these structural modifications of the parent drug may simply support a more stable physical interaction between the active compounds and their biomolecular target. Even if additional assays related to toxicity on human cells, genotoxicity, in vivo experiments, and mechanism of action will be required to estimate their real potential, these biological results revealed that these two compounds constitute promising candidates in the search for improved therapies against $L(V$.) braziliensis and $L$. (L.) mexicana.

\section{4 | EXPERIMENTAL}

\section{1 | Chemistry}

\subsection{1 | General}

Melting points were determined on a Thomas micro hot stage apparatus and are uncorrected. The IR spectra were recorded on a Shimadzu model 470 ( $\mathrm{KBr}$ pellets) or a Nicolet IS5FT-IR (ID3 Zn-Se) spectrophotometer. The ${ }^{1} \mathrm{H}$ and ${ }^{13} \mathrm{C}$ NMR spectra were recorded using a Bruker Avance $300(300 \mathrm{MHz} / 75.5 \mathrm{MHz})$ spectrometer using $\mathrm{CDCl}_{3}$ or Acetone- $d_{6}$ as the solvent, and are reported in ppm downfield from the residual $\mathrm{CHCl}_{3}$ or acetone signals. Elemental analyses were obtained using a Perkin Elmer $2400 \mathrm{CHN}$ elemental analyzer, and the results were within $\pm 0.4 \%$ of the predicted values. Chemical reagents were purchased from Aldrich Chemical Co, USA. All solvents were distilled and dried in the usual 


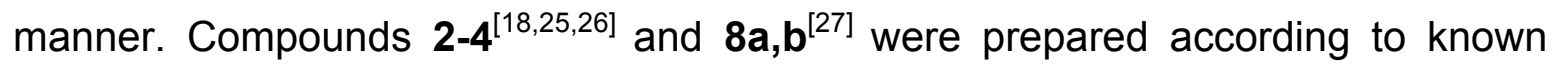
procedures.

\subsection{2 | Synthesis of 2-[2-(2-Methyl-5-nitro-1H-imidazol-1-yl)ethylthio]ethanol} (5)

A stirred solution of $4(5.3 \mathrm{mmol})$, 2-mercaptoethanol $(10.6 \mathrm{mmol})$, and potassium carbonate $(1.8 \mathrm{~g}, 12.7 \mathrm{mmol})$ in acetonitrile $(50 \mathrm{~mL})$ was refluxed for $12 \mathrm{~h}$, after which time it was concentrated under vacuum. The resulting residue was partitioned between ethyl acetate and water. The organic layer was separated and washed with brine, dried over anhydrous $\mathrm{MgSO}_{4}$, filtered and concentrated to yield crude product, which was purified by column chromatography, first EtOAc/hexane (1:1), then $\mathrm{CH}_{2} \mathrm{Cl}_{2} / \mathrm{MeOH}$ (9.5:0.5). yield: $77 \%$; Mp. $79-80^{\circ} \mathrm{C}$; IR $(\mathrm{KBr}) \mathrm{cm}^{-1}: 3344$, 1536, 1478, 1465, 1420; ${ }^{1} \mathrm{H}$ NMR CDCl $\mathrm{CD}_{3} \mathrm{ppm}: 2.53$ (s, 3H, $\mathrm{CH}_{3}$ ), 2.70 (t, $2 \mathrm{H}, \mathrm{CH}_{2}$ $J=5.9 \mathrm{~Hz}$ ), 2.90 (t, $2 \mathrm{H}, \mathrm{CH}_{2} J=5.9 \mathrm{~Hz}$ ), $3.75\left(\mathrm{t}, 2 \mathrm{H}, \mathrm{CH}_{2} J=5.9 \mathrm{~Hz}\right), 4.47(\mathrm{t}, 2 \mathrm{H}$, $\mathrm{CH}_{2} \mathrm{~J}=5.9 \mathrm{~Hz}$ ), 7.97 (s, $\left.1 \mathrm{H}, \mathrm{H}_{4}\right) ;{ }^{13} \mathrm{C} \mathrm{NMR} \mathrm{CDCl}{ }_{3} \delta$ ppm: 14.4, 31.7, 35.5, 46.3, 61.3, 133.1, 138.5, 150.5. Anal. calcd. for $\mathrm{C}_{8} \mathrm{H}_{13} \mathrm{~N}_{3} \mathrm{O}_{3} \mathrm{~S}: \mathrm{C}, 41.55 ; \mathrm{H}, 5.67 ; \mathrm{N}, 18.17$. Found: C, 41.59; H, 5.68; N, 18.35 .

\subsection{3 | General procedure for the preparation of ethyl sulfanyl ethyl benzoate derivatives $7 a-1$}

To an ice-cold stirred solution of substituted benzoic acid $(0.3 \mathrm{mmol})$ in dry $\mathrm{CH}_{2} \mathrm{Cl}_{2}$ $(10 \mathrm{~mL})$ was added EDCI $(0.3 \mathrm{mmol})$ and DMAP $(0.3 \mathrm{mmol})$. The resulting mixture was stirred at $0{ }^{\circ} \mathrm{C}$ for $30 \mathrm{~min}$, after which time was added the alcohol 5 (0.26 $\mathrm{mmol})$. The resulting mixture was stirred for $12 \mathrm{~h}$ and monitored by TLC, eluting with cyclohexane/EtOAc (7:3). The reaction mixture was quenched with sat. aq. $\mathrm{NaHCO}_{3},(20 \mathrm{~mL})$, and the layers were separated. The aqueous layer was extracted with $\mathrm{CH}_{2} \mathrm{Cl}_{2}(2 \times 20 \mathrm{~mL})$, and the combined organic layers were washed with water $(50 \mathrm{~mL})$, and brine $(50 \mathrm{~mL})$, dried over $\mathrm{Na}_{2} \mathrm{SO}_{4}$, filtered and concentrated in vacuum. Purification by column chromatography furnished the benzoate derivatives 7a-I. 
(7a)

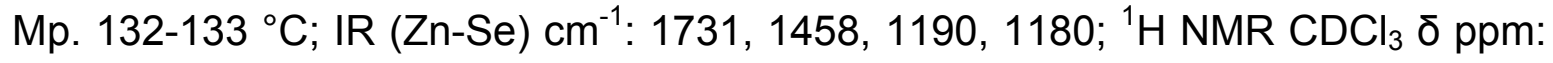
2.50 (s, 3H, CH $\mathrm{CH}_{3}, 2.88$ (t, 2H, $\mathrm{CH}_{2} J=6.7 \mathrm{~Hz}$ ), 2.97 (t, $2 \mathrm{H}, \mathrm{CH}_{2} J=7.1 \mathrm{~Hz}$ ), 3.87 (s, $\left.3 \mathrm{H}, \mathrm{OCH}_{3}\right), 4.43\left(\mathrm{t}, 2 \mathrm{H}, \mathrm{CH}_{2} J=6.6 \mathrm{~Hz}\right), 4.47\left(\mathrm{t}, 2 \mathrm{H}, \mathrm{CH}_{2} J=7.1 \mathrm{~Hz}\right), 6.96(\mathrm{~m}, 2 \mathrm{H}$, $\operatorname{Ar}), 7.46(\mathrm{~m}, 1 \mathrm{H}, \mathrm{Ar}), 7.77(\mathrm{dd}, 1 \mathrm{H}, J=7.9,1.9 \mathrm{~Hz}), 7.92\left(\mathrm{~s}, 1 \mathrm{H}, \mathrm{H}_{4}\right) ;{ }^{13} \mathrm{C} N M R$ $\mathrm{CDCl}_{3}$ ठ ppm: $14.5,31.1,32.0,46.2,56.0,63.6,112.2,119.6,120.3,131.7,133.3$, 133.9, 150.6, 159.3, 165.8. Anal. calcd. for $\mathrm{C}_{16} \mathrm{H}_{19} \mathrm{~N}_{3} \mathrm{O}_{5} \mathrm{~S}$ : C, 52.59; $\mathrm{H}, 5.24 ; \mathrm{N}$, 11.50. Found: C, 52.63; H, 5.27; N, 11.72.

\section{2-\{[2-(2-Methyl-5-nitro-1H-imidazol-1-yl)ethyl]sulfanyl\}ethyl}

4-methoxybenzoate (7b)

Mp. $138-140{ }^{\circ} \mathrm{C}$; IR (Zn-Se) cm ${ }^{-1}: 1740,1472,1210,1187 ;{ }^{1} \mathrm{H}$ NMR $\mathrm{CDCl}_{3} \delta$ ppm: $2.50\left(\mathrm{~s}, 3 \mathrm{H}, \mathrm{CH}_{3}\right), 2.86\left(\mathrm{t}, 2 \mathrm{H}, \mathrm{CH}_{2} J=6.7 \mathrm{~Hz}\right), 2.95\left(\mathrm{t}, 2 \mathrm{H}, \mathrm{CH}_{2} \mathrm{~J}=6.0 \mathrm{~Hz}\right), 3.83$ $\left(\mathrm{s}, 3 \mathrm{H}, \mathrm{OCH}_{3}\right), 4.41\left(\mathrm{t}, 2 \mathrm{H}, \mathrm{CH}_{2} \mathrm{~J}=6.0 \mathrm{~Hz}\right), 4.46\left(\mathrm{t}, 2 \mathrm{H}, \mathrm{CH}_{2} \mathrm{~J}=6.0 \mathrm{~Hz}\right), 6.89$ (d, $\left.2 \mathrm{H}, \mathrm{H}_{3,5} \mathrm{~J}=9.0 \mathrm{~Hz}\right), 7.92\left(\mathrm{~s}, 1 \mathrm{H}, \mathrm{H}_{4}\right), 7.94\left(\mathrm{~d}, 2 \mathrm{H}, \mathrm{H}_{2,6} \mathrm{~J}=9.0 \mathrm{~Hz}\right) ;{ }^{13} \mathrm{C} \mathrm{NMR} \mathrm{CDCl}_{3}$ $\delta$ ppm: 14.5, 31.1, 31.9, 46.2, 55.5, 63.2, 113.7, 122.1, 131.7, 133.2, 138.4, 150.5, 163.6, 166.0. Anal. calcd. for $\mathrm{C}_{16} \mathrm{H}_{19} \mathrm{~N}_{3} \mathrm{O}_{5} \mathrm{~S}$ : C, 52.59; $\mathrm{H}, 5.24 ; \mathrm{N}, 11.50$. Found: $\mathrm{C}$, $52.67 ; \mathrm{H}, 5.25 ; \mathrm{N}, 11.61$.

2-\{[2-(2-Methyl-5-nitro-1H-imidazol-1-yl)ethyl]sulfanyl\}ethyl 2,3-dimethoxybenzoate (7c)

Mp. $136-138{ }^{\circ} \mathrm{C}$; IR (Zn-Se) $\mathrm{cm}^{-1}: 1723,1523,1458,1421 ;{ }^{1} \mathrm{H}$ NMR $\mathrm{CDCl}_{3} \delta \mathrm{ppm}$ : $2.49\left(\mathrm{~s}, 3 \mathrm{H}, \mathrm{CH}_{3}\right), 2.87\left(\mathrm{t}, 2 \mathrm{H}, \mathrm{CH}_{2} \mathrm{~J}=6.7 \mathrm{~Hz}\right), 2.95\left(\mathrm{t}, 2 \mathrm{H}, \mathrm{CH}_{2} \mathrm{~J}=7.1 \mathrm{~Hz}\right), 3.85$ $\left(\mathrm{s}, 3 \mathrm{H}, \mathrm{OCH}_{3}\right), 3.87\left(\mathrm{~s}, 3 \mathrm{H}, \mathrm{OCH}_{3}\right), 4.43\left(\mathrm{t}, 2 \mathrm{H}, \mathrm{CH}_{2} \mathrm{~J}=6.7 \mathrm{~Hz}\right), 4.46\left(\mathrm{t}, 2 \mathrm{H}, \mathrm{CH}_{2} \mathrm{~J}\right.$ $=7.1 \mathrm{~Hz}), 7.05(\mathrm{~m}, 2 \mathrm{H}, \mathrm{Ar}), 7.28(\mathrm{~m}, 1 \mathrm{H}, \mathrm{Ar}), 7.91\left(\mathrm{~s}, 1 \mathrm{H}, \mathrm{H}_{4}\right) ;{ }^{13} \mathrm{C} \mathrm{NMR} \mathrm{CDCl}_{3} \delta$ ppm: 14.5, 31.0, 31.9, 46.1, 56.1, 61.6, 63.6, 116.1, 122.2, 123.9, 125.7, 133.2, 149.2, 150.5, 153.6, 166.0. Anal. calcd. for $\mathrm{C}_{17} \mathrm{H}_{21} \mathrm{~N}_{3} \mathrm{O}_{6} \mathrm{~S}$ : C, 51.64; $\mathrm{H}, 5.35 ; \mathrm{N}$, 10.63. Found: C, 51.69; $\mathrm{H}, 5.38 ; \mathrm{N}, 10.83$. 
2-\{[2-(2-Methyl-5-nitro-1H-imidazol-1-yl)ethyl]sulfanyl\}ethyl 2,4-dimethoxybenzoate (7d)

Mp. $141-143{ }^{\circ} \mathrm{C}$; IR (Zn-Se) $\mathrm{cm}^{-1}: 2941,1715,1609,1458,1417,1237 ;{ }^{1} \mathrm{H}$ NMR $\mathrm{CDCl}_{3} \delta$ ppm: $2.51\left(\mathrm{~s}, 3 \mathrm{H}, \mathrm{CH}_{3}\right), 2.87\left(\mathrm{t}, 2 \mathrm{H}, \mathrm{CH}_{2} \mathrm{~J}=6.7 \mathrm{~Hz}\right), 2.97\left(\mathrm{t}, 2 \mathrm{H}, \mathrm{CH}_{2} \mathrm{~J}=\right.$ $7.0 \mathrm{~Hz}$ ), $3.84\left(\mathrm{~s}, 3 \mathrm{H}, \mathrm{OCH}_{3}\right), 3.86\left(\mathrm{~s}, 3 \mathrm{H}, \mathrm{OCH}_{3}\right), 4.41\left(\mathrm{t}, 2 \mathrm{H}, \mathrm{CH}_{2} \mathrm{~J}=6.7 \mathrm{~Hz}\right), 4.48$ (t, $\left.2 \mathrm{H}, \mathrm{CH}_{2} \mathrm{~J}=7.0 \mathrm{~Hz}\right), 6.48\left(\mathrm{~m}, 2 \mathrm{H}, \mathrm{H}_{3^{\prime}, 5^{\prime}}\right), 7.82\left(\mathrm{~d}, 1 \mathrm{H}, \mathrm{H}_{6^{\prime}} \mathrm{J}=8.9 \mathrm{~Hz}\right), 7.91(\mathrm{~s}, 1 \mathrm{H}$, $\left.\mathrm{H}_{4}\right) ;{ }^{13} \mathrm{C}$ NMR $\mathrm{CDCl}_{3} \delta$ ppm: 14.4, 31.1, 32.2, 45.9, 55.7, 55.9, 64.1, 99.1, 105.1, 110.1, 133.7, 134.3, 161.6, 164.8, 165. Anal. calcd. for $\mathrm{C}_{17} \mathrm{H}_{21} \mathrm{~N}_{3} \mathrm{O}_{6} \mathrm{~S}: \mathrm{C}, 51.64 ; \mathrm{H}$, 5.35; N, 10.63. Found: C, 51.72; H, 5.35; N, 10.87.

2-\{[2-(2-Methyl-5-nitro-1H-imidazol-1-yl)ethyl]sulfanyl\}ethyl 2,5-dimethoxybenzoate (7e)

Mp. $152-154{ }^{\circ} \mathrm{C}$; IR $(\mathrm{Zn}-\mathrm{Se}) \mathrm{cm}^{-1}: 1745,1499,1224,1202 ;{ }^{1} \mathrm{H} \mathrm{NMR} \mathrm{CDCl}_{3} \delta \mathrm{ppm}$ : 2.50 (s, 3H, $\mathrm{CH}_{3}$ ), $2.88\left(\mathrm{t}, 2 \mathrm{H}, \mathrm{CH}_{2} \mathrm{~J}=6.7 \mathrm{~Hz}\right), 2.97\left(\mathrm{t}, 2 \mathrm{H}, \mathrm{CH}_{2} \mathrm{~J}=7.1 \mathrm{~Hz}\right), 3.77$ $\left(\mathrm{s}, 3 \mathrm{H}, \mathrm{OCH}_{3}\right), 3.82\left(\mathrm{~s}, 3 \mathrm{H}, \mathrm{OCH}_{3}\right), 4.43\left(\mathrm{t}, 2 \mathrm{H}, \mathrm{CH}_{2} \mathrm{~J}=6.7 \mathrm{~Hz}\right), 4.47\left(\mathrm{t}, 2 \mathrm{H}, \mathrm{CH}_{2} \mathrm{~J}=\right.$ $7.0 \mathrm{~Hz}), 6.90\left(\mathrm{~d}, 1 \mathrm{H}, \mathrm{H}_{3} \mathrm{~J}=9.1 \mathrm{~Hz}\right), 7.01\left(\mathrm{dd}, 1 \mathrm{H}, \mathrm{H}_{4} \cdot J=9.1,3.2 \mathrm{~Hz}\right), 7.31(\mathrm{~d}, 1 \mathrm{H}$, $\left.\mathrm{H}_{6} \cdot J=3.2 \mathrm{~Hz}\right), 7.92\left(\mathrm{~s}, 1 \mathrm{H}, \mathrm{H}_{4}\right) ;{ }^{13} \mathrm{C} \mathrm{NMR} \mathrm{CDCl}_{3} \delta \mathrm{ppm:} \mathrm{14.5,} \mathrm{31.1,} \mathrm{32.0,} \mathrm{46.2,}$ 55.9, 56.8, 63.7, 113.9, 116.3, 119.7, 120.1, 133.2, 150.6, 153.1, 153.7, 165.7. Anal. calcd. for $\mathrm{C}_{17} \mathrm{H}_{21} \mathrm{~N}_{3} \mathrm{O}_{6} \mathrm{~S}$ : C, 51.64; $\mathrm{H}, 5.35 ; \mathrm{N}, 10.63$. Found: $\mathrm{C}, 51.66 ; \mathrm{H}$, $5.37 ; \mathrm{N}, 10.72$.

2-\{[2-(2-Methyl-5-nitro-1H-imidazol-1-yl)ethyl]sulfanyl\}ethyl 2,4,5-trimethoxybenzoate (7f)

Mp. 161-163 ${ }^{\circ} \mathrm{C}$; IR (Zn-Se) $\mathrm{cm}^{-1}:$ 1705, 1480, 1203, 1191; ${ }^{1} \mathrm{H} \mathrm{NMR} \mathrm{CDCl} \mathrm{N}_{3} \delta \mathrm{ppm}$ : $2.50\left(\mathrm{~s}, 3 \mathrm{H}, \mathrm{CH}_{3}\right), 2.86\left(\mathrm{t}, 2 \mathrm{H}, \mathrm{CH}_{2} \mathrm{~J}=6.7 \mathrm{~Hz}\right), 2.96\left(\mathrm{t}, 2 \mathrm{H}, \mathrm{CH}_{2} \mathrm{~J}=7.1 \mathrm{~Hz}\right), 3.83$ $\left(\mathrm{s}, 3 \mathrm{H}, \mathrm{OCH}_{3}\right), 3.85\left(\mathrm{~s}, 3 \mathrm{H}, \mathrm{OCH}_{3}\right), 3.91\left(\mathrm{~s}, 3 \mathrm{H}, \mathrm{OCH}_{3}\right), 4.40\left(\mathrm{t}, 2 \mathrm{H}, \mathrm{CH}_{2} \mathrm{~J}=6.7\right.$ $\mathrm{Hz}$ ), 4.46 (t, 2H, $\mathrm{CH}_{2} \mathrm{~J}=7.0 \mathrm{~Hz}$ ), 6.49 (s, 1H, $\mathrm{H}_{3^{\prime}}$ ), 7.36 (s, 1H, $\mathrm{H}_{6^{\prime}}$ ), 7.91 (s, 1H, $\left.\mathrm{H}_{4}\right) ;{ }^{13} \mathrm{C}$ NMR $\mathrm{CDCl}_{3} \delta$ ppm: 14.5, 31.1, 32.0, 46.2, 56.1, 56.5, 57.0, 63.3, 97.7, $110.1,114.5,133.2,142.6,150.6,153.9$, 156.0, 165.3. Anal. calcd. for $\mathrm{C}_{18} \mathrm{H}_{23} \mathrm{~N}_{3} \mathrm{O}_{7} \mathrm{~S}: \mathrm{C}, 50.82 ; \mathrm{H}, 5.45 ; \mathrm{N}, 9.88$. Found: $\mathrm{C}, 50.85 ; \mathrm{H}, 5.47 ; \mathrm{N}, 10.07$. 
benzoate $(7 \mathrm{~g})$

Mp. $160-162{ }^{\circ} \mathrm{C}$; IR (Zn-Se) $\mathrm{cm}^{-1}: 1704,1217,1120 ;{ }^{1} \mathrm{H}$ NMR $\mathrm{CDCl}_{3} \delta$ ppm: 2.50 (s, 3H, $\mathrm{CH}_{3}$ ), 2.86 (t, $2 \mathrm{H}, \mathrm{CH}_{2} \mathrm{~J}=6.8 \mathrm{~Hz}$ ), 2.95 (t, $\left.2 \mathrm{H}, \mathrm{CH}_{2} J=7.2 \mathrm{~Hz}\right), 3.87(\mathrm{~s}, 9 \mathrm{H}$, $\mathrm{OCH}_{3}$ ), 4.42 (t, $\left.2 \mathrm{H}, \mathrm{CH}_{2} J=6.8 \mathrm{~Hz}\right), 4.46\left(\mathrm{t}, 2 \mathrm{H}, \mathrm{CH}_{2} J=7.1 \mathrm{~Hz}\right), 7.24(\mathrm{~s}, 2 \mathrm{H}$, $\left.\mathrm{H}_{2^{\prime}, 6^{\prime}}\right), 7.91\left(\mathrm{~s}, 1 \mathrm{H}, \mathrm{H}_{4}\right) ;{ }^{13} \mathrm{C} \mathrm{NMR} \mathrm{CDCl}_{3} \delta \mathrm{ppm}: 14.5,31.0,31.9,46.2,56.3,60.9$, $63.5,106.9,124.7,133.2,142.5,150.5,153.0,165.9$. Anal. calcd. for $\mathrm{C}_{18} \mathrm{H}_{23} \mathrm{~N}_{3} \mathrm{O}_{7} \mathrm{~S}$ : C, 50.82; H, 5.45; N, 9.88. Found: C, 50.83; H, 5.45; N, 10.12.

\section{2-\{[2-(2-Methyl-5-nitro-1H-imidazol-1-yl)ethyl]sulfanyl\}ethyl}

4-methoxy-3-nitrobenzoate (7h)

Mp. 118-120 ${ }^{\circ} \mathrm{C}$; IR (Zn-Se) $\mathrm{cm}^{-1}: 2923,2360,2325,1711,1514 ;{ }^{1} \mathrm{H} \mathrm{NMR} \mathrm{CDCl}_{3} \delta$ ppm: 2.54 (s, 3H, CH $\mathrm{CH}_{3}, 2.89$ (t, $2 \mathrm{H}, \mathrm{CH}_{2} J=6.6 \mathrm{~Hz}$ ), 2.97 (t, $2 \mathrm{H}, \mathrm{CH}_{2} J=7.2 \mathrm{~Hz}$ ), $4.03\left(\mathrm{~s}, 3 \mathrm{H}, \mathrm{OCH}_{3}\right), 4.47\left(\mathrm{t}, 2 \mathrm{H}, \mathrm{CH}_{2} \mathrm{~J}=6.6 \mathrm{~Hz}\right), 4.50\left(\mathrm{t}, 2 \mathrm{H}, \mathrm{CH}_{2} \mathrm{~J}=7.1 \mathrm{~Hz}\right), 7.15$ $\left(\mathrm{d}, 1 \mathrm{H}, \mathrm{H}_{5} \cdot J=8.9 \mathrm{~Hz}\right), 7.94\left(\mathrm{~s}, 1 \mathrm{H}, \mathrm{H}_{4}\right), 8.19\left(\mathrm{dd}, 1 \mathrm{H}, \mathrm{H}_{6} \cdot J=8.8,2.2 \mathrm{~Hz}\right), 8.47(\mathrm{~d}$, $\left.1 \mathrm{H}, \mathrm{H}_{2} \cdot J=2.2 \mathrm{~Hz}\right) ;{ }^{13} \mathrm{C} \mathrm{NMR} \mathrm{CDCl}_{3} \delta \mathrm{ppm}: 14.6,31.1,31.9,46.2,57.0,63.8$, $113.4,122.3,127.4,133.4,135.5,139.4,150.6,156.4,164.3$. Anal. calcd. for $\mathrm{C}_{16} \mathrm{H}_{18} \mathrm{~N}_{4} \mathrm{O}_{7} \mathrm{~S}: \mathrm{C}, 46.83 ; \mathrm{H}, 4.42 ; \mathrm{N}, 13.65$. Found: $\mathrm{C}, 46.89 ; \mathrm{H}, 4.45 ; \mathrm{N}, 13.81$.

2-\{[2-(2-Methyl-5-nitro-1H-imidazol-1-yl)ethyl]sulfanyl\}ethyl 3,5-dimethylbenzoate (7i)

Mp. $85-87{ }^{\circ} \mathrm{C}$; IR (Zn-Se) $\mathrm{cm}^{-1}: 2921,1703,1519,1515 ;{ }^{1} \mathrm{H} \mathrm{NMR} \mathrm{CDCl}_{3} \delta \mathrm{ppm}$ : $2.34\left(\mathrm{~s}, 6 \mathrm{H}, \mathrm{CH}_{3}\right), 2.54\left(\mathrm{~s}, 3 \mathrm{H}, \mathrm{CH}_{3}\right), 2.89\left(\mathrm{t}, 2 \mathrm{H}, \mathrm{CH}_{2} \mathrm{~J}=6.7 \mathrm{~Hz}\right), 2.98\left(\mathrm{t}, 2 \mathrm{H}, \mathrm{CH}_{2}\right.$ $J=7.1 \mathrm{~Hz}), 4.45\left(\mathrm{t}, 2 \mathrm{H}, \mathrm{CH}_{2} J=6.7 \mathrm{~Hz}\right), 4.49\left(\mathrm{t}, 2 \mathrm{H}, \mathrm{CH}_{2} J=7.1 \mathrm{~Hz}\right), 7.18(\mathrm{~s}, 1 \mathrm{H}$, $\left.\mathrm{H}_{4}{ }^{\prime}\right), 7.62\left(\mathrm{~s}, 2 \mathrm{H}, \mathrm{H}_{2^{\prime}, 6^{\prime}}\right), 7.96\left(\mathrm{~s}, 1 \mathrm{H}, \mathrm{H}_{4}\right) ;{ }^{13} \mathrm{C} \mathrm{NMR} \mathrm{CDCl}_{3} \delta \mathrm{ppm:} \mathrm{14.6,} \mathrm{21.2,} \mathrm{31.1,}$ $32.0,46.3,63.5,127.4,129.7,133.2,135.0,138.2,150.6,166.8$. Anal. calcd. for $\mathrm{C}_{17} \mathrm{H}_{21} \mathrm{~N}_{3} \mathrm{O}_{4} \mathrm{~S}: \mathrm{C}, 56.18 ; \mathrm{H}, 5.82 ; \mathrm{N}, 11.56$. Found: $\mathrm{C}, 56.23 ; \mathrm{H}, 5.82 ; \mathrm{N}, 11.87$.

2-\{[2-(2-Methyl-5-nitro-1H-imidazol-1-yl)ethyl]sulfanyl\}ethyl 4-tert-butylbenzoate (7j) Mp. 83-85 ${ }^{\circ} \mathrm{C}$; IR (Zn-Se) cm ${ }^{-1}:$ 2962, 1711, 1605, 1527, 1454, 1352; ${ }^{1} \mathrm{H}$ NMR $\mathrm{CDCl}_{3} \delta$ ppm: $1.36\left(\mathrm{~s}, 9 \mathrm{H}, \mathrm{CH}_{3}\right), 2.56\left(\mathrm{~s}, 3 \mathrm{H}, \mathrm{CH}_{3}\right), 2.92\left(\mathrm{t}, 2 \mathrm{H}, \mathrm{CH}_{2} \mathrm{~J}=6.0 \mathrm{~Hz}\right.$ ), 
$3.01\left(\mathrm{t}, 2 \mathrm{H}, \mathrm{CH}_{2} J=7.3 \mathrm{~Hz}\right), 4.49\left(\mathrm{t}, 2 \mathrm{H}, \mathrm{CH}_{2} J=6.6 \mathrm{~Hz}\right), 4.53\left(\mathrm{t}, 2 \mathrm{H}, \mathrm{CH}_{2} J=7.1\right.$ $\mathrm{Hz}), 7.49\left(\mathrm{~d}, 2 \mathrm{H}, \mathrm{H}_{3^{\prime}, 5^{\prime}} \mathrm{J}=8.9 \mathrm{~Hz}\right), 7.97\left(\mathrm{~d}, 2 \mathrm{H}, \mathrm{H}_{2^{\prime} 6^{\prime}} \mathrm{J}=8.7 \mathrm{~Hz}\right), 7.99\left(\mathrm{~s}, 1 \mathrm{H}, \mathrm{H}_{4}\right)$;

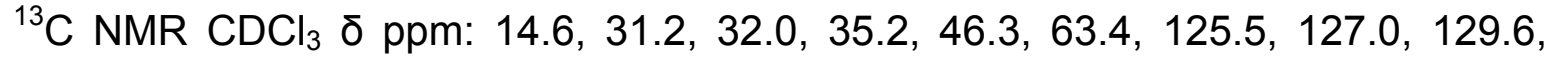
133.2, 150.6, 157.0, 166.4. Anal. calcd. for $\mathrm{C}_{19} \mathrm{H}_{25} \mathrm{~N}_{3} \mathrm{O}_{4} \mathrm{~S}$ : C, 58.29; $\mathrm{H}, 6.44 ; \mathrm{N}$, 10.73. Found: C, 58.35; $\mathrm{H}, 6.46 ; \mathrm{N}, 10.97$.

2-\{[2-(2-Methyl-5-nitro-1H-imidazol-1-yl)ethyl]sulfanyl\}ethyl 5-methyl-2-nitrobenzoate (7k)

Mp. 88-90 ${ }^{\circ} \mathrm{C}$; IR (Zn-Se) cm ${ }^{-1}: 2970,1728,1589,1523,1458 ;{ }^{1} \mathrm{H} \mathrm{NMR} \mathrm{CDCl}_{3} \delta$ ppm: 2.47 (s, 3H, $\left.\mathrm{CH}_{3}\right), 2.52\left(\mathrm{~s}, 3 \mathrm{H}, \mathrm{CH}_{3}\right), 2.86\left(\mathrm{t}, 2 \mathrm{H}, \mathrm{CH}_{2} \mathrm{~J}=6.0 \mathrm{~Hz}\right), 2.94(\mathrm{t}, 2 \mathrm{H}$, $\left.\mathrm{CH}_{2} J=7.2 \mathrm{~Hz}\right), 4.46\left(\mathrm{~m}, 4 \mathrm{H}, \mathrm{CH}_{2}\right), 7.40\left(\mathrm{dd}, 1 \mathrm{H}, \mathrm{H}_{4} \cdot \mathrm{J}=8.3,2.6 \mathrm{~Hz}\right), 7.46(\mathrm{~s}, 1 \mathrm{H}$, $\left.\mathrm{H}_{6^{\prime}}\right), 7.86\left(\mathrm{~d}, 1 \mathrm{H}, \mathrm{H}_{3^{\prime}} \mathrm{J}=8.3 \mathrm{~Hz}\right), 7.92\left(\mathrm{~s}, 1 \mathrm{H}, \mathrm{H}_{4}\right) ;{ }^{13} \mathrm{C} \mathrm{NMR} \mathrm{CDCl}_{3} \delta \mathrm{ppm}: 14.5$, 21.5, 30.4, 31.9, 46.1, 64.8, 124.3, 128.0, 130.1, 132.1, 133.3, 145.0, 150.6, 165.8. Anal. calcd. for $\mathrm{C}_{16} \mathrm{H}_{18} \mathrm{~N}_{4} \mathrm{O}_{6} \mathrm{~S}$ : C, 48.73; $\mathrm{H}, 4.60 ; \mathrm{N}, 14.21$. Found: $\mathrm{C}, 48.72 ; \mathrm{H}$, $4.61 ; \mathrm{N}, 14.45$.

2-\{[2-(2-Methyl-5-nitro-1H-imidazol-1-yl)ethyl]sulfanyl\}ethyl

4-trifluoromethylbenzoate (7I)

Mp. 92-94 ${ }^{\circ} \mathrm{C}$; IR (Zn-Se) cm${ }^{-1}: 3039,1711,1519,1450,1360 ;{ }^{1}{\mathrm{H} \mathrm{NMR} \mathrm{CDCl}_{3} \delta} \delta$ ppm: 2.52 (s, $3 \mathrm{H}, \mathrm{CH}_{3}$ ), 2.89 (t, $2 \mathrm{H}, \mathrm{CH}_{2} \mathrm{~J}=6.7 \mathrm{~Hz}$ ), 2.96 (t, $2 \mathrm{H}, \mathrm{CH}_{2} \mathrm{~J}=7.1 \mathrm{~Hz}$ ), $4.48\left(\mathrm{~m}, 4 \mathrm{H}, \mathrm{CH}_{2}\right), 7.69\left(\mathrm{~d}, 2 \mathrm{H}, \mathrm{H}_{3^{\prime}, 5^{\prime}} \mathrm{J}=8.1 \mathrm{~Hz}\right), 7.93\left(\mathrm{~s}, 1 \mathrm{H}, \mathrm{H}_{4}\right), 8.12\left(\mathrm{~d}, 2 \mathrm{H}, \mathrm{H}_{2^{\prime}, 6^{\prime}}\right.$ $J=8.1 \mathrm{~Hz}) ;{ }^{19} \mathrm{~F} \mathrm{NMR}\left(\mathrm{CDCl}_{3}, 282 \mathrm{MHz}\right) \delta 63.14 ;{ }^{13} \mathrm{C} \mathrm{NMR} \mathrm{CDCl}_{3} \delta \mathrm{ppm:} \mathrm{14.6}$, $31.0,31.9,46.2,63.9,125.55,125.60,130.1,133.3,150.6,165.2$. Anal. calcd. for $\mathrm{C}_{16} \mathrm{H}_{16} \mathrm{~F}_{3} \mathrm{~N}_{3} \mathrm{O}_{4} \mathrm{~S}: \mathrm{C}, 47.64 ; \mathrm{H}, 4.00 ; \mathrm{N}, 10.42$. Found: $\mathrm{C}, 47.67 ; \mathrm{H}, 4.03 ; \mathrm{N}, 10.67$.

\subsubsection{General procedure for the preparation of ethyl sulfanyl ethyl di- and trihydroxybenzoates $9 a$ and $9 b$}

To an ice-cold stirred solution of 3,4-bis(tert-butyldimethylsilyloxy)benzoic acid $(\mathbf{8 a})^{[27]}$ or $3,4,5$-tris(tert-butyldimethylsilyloxy)benzoic acid $(\mathbf{8 b})^{[27]}(0.3 \mathrm{mmol})$ in dry $\mathrm{CH}_{2} \mathrm{Cl}_{2}(10 \mathrm{~mL})$ was added EDCl $(0.3 \mathrm{mmol})$ and DMAP $(0.3 \mathrm{mmol})$. The resulting mixture was stirred at $0^{\circ} \mathrm{C}$ for $30 \mathrm{~min}$, after which time was added the alcohol 5 
$(0.26 \mathrm{mmol})$. The resulting mixture was stirred for $12 \mathrm{~h}$ and monitored by TLC, eluting with cyclohexane/EtOAc (7:3). The reaction mixture was quenched with sat. aq. $\mathrm{NaHCO}_{3}(20 \mathrm{~mL})$ and the layers were separated. The aqueous layer was extracted with $\mathrm{CH}_{2} \mathrm{Cl}_{2}(2 \times 20 \mathrm{~mL})$, and the combined organic layers were washed with water $(50 \mathrm{~mL})$, brine $(50 \mathrm{~mL})$, dried over $\mathrm{Na}_{2} \mathrm{SO}_{4}$, filtered and concentrated in vacuum. The subsequent desilylation step was adapted from our previously described procedure. ${ }^{[27]}$ To a stirred ice-cold solution of this crude material in THF $(25 \mathrm{~mL})$ was added dropwise acetic acid $(1.5 \mathrm{mmol})$ and tetrabutylammonium fluoride (1.5 mmol, TBAF 0.1M in THF). The resulting mixture was stirred for $3 \mathrm{~h}$ and monitored by TLC, eluting with $\mathrm{CH}_{2} \mathrm{Cl}_{2} / \mathrm{MeOH}$ (9.5:0.5). After evaporation of the solvent, $\mathrm{CH}_{2} \mathrm{Cl}_{2}(50 \mathrm{~mL})$ was added. The organic layer was washed with sat. aq. $\mathrm{NaHCO}_{3}(50 \mathrm{~mL})$, water $(50 \mathrm{~mL})$, and brine $(50 \mathrm{~mL})$, dried over $\mathrm{Na}_{2} \mathrm{SO}_{4}$, filtered and concentrated in vacuum. The resulting white powder was purified by column chromatography, eluting with $\mathrm{CH}_{2} \mathrm{Cl}_{2} / \mathrm{MeOH}(9.5: 0.5-9: 1)$.

2-\{[2-(2-Methyl-5-nitro-1H-imidazol-1-yl)ethyl]sulfanyl\}ethyl 3,4-dihydroxybenzoate (9a)

Mp. $185-187^{\circ} \mathrm{C}$; IR (Zn-Se) cm ${ }^{-1}: 2966,1699,1589,1274,1176 ;{ }^{1} \mathrm{H} \mathrm{NMR} \mathrm{CDCl}_{3} \delta$ ppm: $2.56\left(\mathrm{~s}, 3 \mathrm{H}, \mathrm{CH}_{3}\right), 2.95\left(\mathrm{t}, 2 \mathrm{H}, \mathrm{CH}_{2} J=6.7 \mathrm{~Hz}\right), 3.08\left(\mathrm{t}, 2 \mathrm{H}, \mathrm{CH}_{2} J=7.0 \mathrm{~Hz}\right.$ ), $4.40\left(\mathrm{t}, 2 \mathrm{H}, \mathrm{CH}_{2} J=6.6 \mathrm{~Hz}\right), 4.61\left(\mathrm{t}, 2 \mathrm{H}, \mathrm{CH}_{2} J=7.2 \mathrm{~Hz}\right), 6.91\left(\mathrm{~d}, 1 \mathrm{H}, \mathrm{H}_{5} \cdot J=8.3\right.$ $\mathrm{Hz}), 7.44\left(\mathrm{dd}, 1 \mathrm{H}, \mathrm{H}_{6} \cdot \mathrm{J}=8.3,2.0 \mathrm{~Hz}\right), 7.51\left(\mathrm{~d}, 1 \mathrm{H}, \mathrm{H}_{2} \mathrm{~J}=2.0 \mathrm{~Hz}\right) ; 7.93\left(\mathrm{~s}, 1 \mathrm{H}, \mathrm{H}_{4}\right)$;

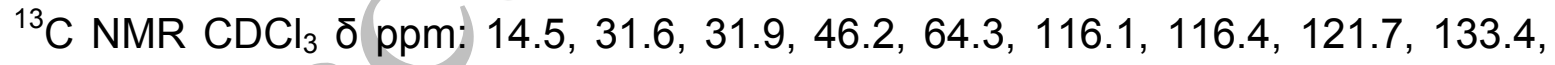
139.0, 146.2, 152.1, 166.7. Anal. calcd. for $\mathrm{C}_{15} \mathrm{H}_{17} \mathrm{~N}_{3} \mathrm{O}_{6} \mathrm{~S}$ : C, 49.04; $\mathrm{H}, 4.66 ; \mathrm{N}$, 11.44. Found: C, 49.10; H, 4.70; N, 11.69.

2-\{[2-(2-Methyl-5-nitro-1H-imidazol-1-yl)ethyl]sulfanyl\}ethyl

3,4,5-trihydroxybenzoate (9b)

Mp. 198-200 ${ }^{\circ} \mathrm{C}$; IR (Zn-Se) $\mathrm{cm}^{-1}: 3367,1696,1684,1225,1171,1040 ;{ }^{1} \mathrm{H}$ NMR acetone- $d_{6} \delta$ ppm: 2.57 (s, 3H, $\mathrm{CH}_{3}$ ), 2.95 (t, $2 \mathrm{H}, \mathrm{CH}_{2} \mathrm{~J}=6.6 \mathrm{~Hz}$ ), $3.09\left(\mathrm{t}, 2 \mathrm{H}, \mathrm{CH}_{2}\right.$ $J=7.0 \mathrm{~Hz}), 4.38\left(\mathrm{t}, 2 \mathrm{H}, \mathrm{CH}_{2} J=6.6 \mathrm{~Hz}\right), 4.62\left(\mathrm{t}, 2 \mathrm{H}, \mathrm{CH}_{2} J=7.2 \mathrm{~Hz}\right), 7.12(\mathrm{~s}, 2 \mathrm{H}$, $\left.\mathrm{H}_{2^{\prime}, 6^{\prime}}\right), 7.93\left(\mathrm{~s}, 1 \mathrm{H}, \mathrm{H}_{4}\right), 8.29$ (bs, $\left.3 \mathrm{H}, \mathrm{OH}\right) ;{ }^{13} \mathrm{C}$ NMR acetone- $d_{6} \delta$ ppm: 14.5, 31.4, 
32.2, 46.8, 64.0, 110.0, 121.7, 133.4, 139.0, 146.2, 152.1, 166.6. Anal. calcd. for $\mathrm{C}_{15} \mathrm{H}_{17} \mathrm{~N}_{3} \mathrm{O}_{7} \mathrm{~S}: \mathrm{C}, 46.99 ; \mathrm{H}, 4.47 ; \mathrm{N}, 10.96$. Found: $\mathrm{C}, 47.05 ; \mathrm{H}, 4.61 ; \mathrm{N}, 11.17$.

\subsection{5 | General procedure for the preparation of ethyl sulfonyl ethyl benzoate derivatives 10a-I}

To an ice-cold stirred solution of substituted ester $7 \mathrm{a}-\mathrm{I}(0.2 \mathrm{mmol})$ in dry $\mathrm{CH}_{2} \mathrm{Cl}_{2}$ (10 $\mathrm{mL}$ ) was added meta-chloroperoxybenzoic acid $(0.6 \mathrm{mmol}$, purity of $70 \%)$ under a $\mathrm{N}_{2}$ atmosphere. The resulting mixture was allowed to warm to room temperature for $6 \mathrm{~h}$. The reaction mixture was quenched with sat. aq. $\mathrm{NaHCO}_{3}(10 \mathrm{~mL})$ and $\mathrm{Na}_{2} \mathrm{~S}_{2} \mathrm{O}_{3}(5 \mathrm{~mL})$. The layers were separated and the aqueous layer was extracted with $\mathrm{CH}_{2} \mathrm{Cl}_{2}(2 \times 25 \mathrm{~mL})$. The combined organic layers were washed with water (50 $\mathrm{mL}$ ) and brine $(50 \mathrm{~mL})$, dried over $\mathrm{Na}_{2} \mathrm{SO}_{4}$, filtered and concentrated in vacuum. Purification by column chromatography, eluting with EtOAc/cyclohexane (9:1), furnished the sulfonyl benzoate derivatives 10a-I.

2-\{[2-(2-Methyl-5-nitro-1H-imidazol-1-yl)ethyl]sulfonyl\}ethyl 2-methoxybenzoate (10a)

Mp. $101-103{ }^{\circ} \mathrm{C}$; IR (Zn-Se) $\mathrm{cm}^{-1}: 2933,1715,1601,1523,1470 ;{ }^{1} \mathrm{H} \mathrm{NMR} \mathrm{CDCl}_{3} \delta$ ppm: $2.53\left(\mathrm{~s}, 3 \mathrm{H}, \mathrm{CH}_{3}\right), 3.45\left(\mathrm{t}, 2 \mathrm{H}, \mathrm{CH}_{2} J=5.6 \mathrm{~Hz}\right), 3.62\left(\mathrm{t}, 2 \mathrm{H}, \mathrm{CH}_{2} J=6.5 \mathrm{~Hz}\right)$, $3.82\left(\mathrm{~s}, 3 \mathrm{H}, \mathrm{OCH}_{3}\right), 4.71\left(\mathrm{t}, 2 \mathrm{H}, \mathrm{CH}_{2} J=5.7 \mathrm{~Hz}\right), 4.76\left(\mathrm{t}, 2 \mathrm{H}, \mathrm{CH}_{2} J=6.7 \mathrm{~Hz}\right), 6.97$ $\left(\mathrm{m}, 2 \mathrm{H}, \mathrm{H}_{4^{\prime}, 5^{\prime}}\right), 7.49\left(\mathrm{~m}, 1 \mathrm{H}, \mathrm{H}_{3^{\prime}}\right), 7.76\left(\mathrm{dd}, 1 \mathrm{H}, \mathrm{H}_{6^{\prime}}, J=7.7,1.8 \mathrm{~Hz}\right), 7.93(\mathrm{~s}, 1 \mathrm{H}$, $\left.\mathrm{H}_{4}\right) ;{ }^{13} \mathrm{C} \mathrm{NMR} \mathrm{CDCl}_{3} \delta \mathrm{ppm}: 14.4,39.1,53.2,53.8,56.0,58.0,112.3,118.5$, 120.6, 132.0, 134.6, 159.3, 165.4. Anal. calcd. for $\mathrm{C}_{16} \mathrm{H}_{19} \mathrm{~N}_{3} \mathrm{O}_{7} \mathrm{~S}$ : C, 48.36; $\mathrm{H}, 4.82$; $\mathrm{N}, 10.57$. Found: $\mathrm{C}, 48.39 ; \mathrm{H}, 4.86 ; \mathrm{N}, 10.79$.

2-\{[2-(2-Methyl-5-nitro-1H-imidazol-1-yl)ethyl]sulfonyl\}ethyl 4-methoxybenzoate (10b)

Mp. 103-105 ${ }^{\circ} \mathrm{C}$; IR (Zn-Se) $\mathrm{cm}^{-1}: 3141,1719,1519,1450 ;{ }^{1} \mathrm{H} \mathrm{NMR} \mathrm{CDCl}_{3} \delta \mathrm{ppm}$ : $2.58\left(\mathrm{~s}, 3 \mathrm{H}, \mathrm{CH}_{3}\right), 3.46\left(\mathrm{t}, 2 \mathrm{H}, \mathrm{CH}_{2} J=5.6 \mathrm{~Hz}\right), 3.58\left(\mathrm{t}, 2 \mathrm{H}, \mathrm{CH}_{2} J=6.6 \mathrm{~Hz}\right), 3.87$ $\left(\mathrm{s}, 3 \mathrm{H}, \mathrm{OCH}_{3}\right), 4.73\left(\mathrm{t}, 2 \mathrm{H}, \mathrm{CH}_{2} \mathrm{~J}=5.8 \mathrm{~Hz}\right), 4.79\left(\mathrm{t}, 2 \mathrm{H}, \mathrm{CH}_{2} \mathrm{~J}=6.6 \mathrm{~Hz}\right), 6.93(\mathrm{~d}$, $\left.2 \mathrm{H}, \mathrm{H}_{3^{\prime}, 5^{\prime}} J=9.0 \mathrm{~Hz}\right), 7.92\left(\mathrm{~d}, 2 \mathrm{H}, \mathrm{H}_{2^{\prime}, 6^{\prime}} \mathrm{J}=9.0 \mathrm{~Hz}\right), 7.95\left(\mathrm{~s}, 1 \mathrm{H}, \mathrm{H}_{4}\right) ;{ }^{13} \mathrm{C} \mathrm{NMR}$ 
$\mathrm{CDCl}_{3} \delta$ ppm: 14.5, 39.0, 53.5, 53.9, 55.7, 57.6, 114.1, 121.2, 131.9, 133.8, 151.3, 164.1, 165.6. Anal. calcd. for $\mathrm{C}_{16} \mathrm{H}_{19} \mathrm{~N}_{3} \mathrm{O}_{7} \mathrm{~S}$ : C, 48.36; $\mathrm{H}, 4.82$; N, 10.57. Found: $\mathrm{C}$, 48.41; H, 4.83; N, 10.81.

2-\{[2-(2-Methyl-5-nitro-1H-imidazol-1-yl)ethyl]sulfonyl\}ethyl 2,3-dimethoxybenzoate (10c)

Mp. $114-116{ }^{\circ} \mathrm{C}$; IR (Zn-Se) $\mathrm{cm}^{-1}: 2361,1711,1503,1450 ;{ }^{1} \mathrm{H}$ NMR $\mathrm{CDCl}_{3} \delta \mathrm{ppm}$ : $2.58\left(\mathrm{~s}, 3 \mathrm{H}, \mathrm{CH}_{3}\right), 3.49\left(\mathrm{t}, 2 \mathrm{H}, \mathrm{CH}_{2} \mathrm{~J}=5.7 \mathrm{~Hz}\right), 3.68\left(\mathrm{t}, 2 \mathrm{H}, \mathrm{CH}_{2} \mathrm{~J}=6.7 \mathrm{~Hz}\right), 3.86$ $\left(\mathrm{s}, 3 \mathrm{H}, \mathrm{OCH}_{3}\right), 3.90\left(\mathrm{~s}, 3 \mathrm{H}, \mathrm{OCH}_{3}\right), 4.77\left(\mathrm{t}, 2 \mathrm{H}, \mathrm{CH}_{2} \mathrm{~J}=5.7 \mathrm{~Hz}\right), 4.80\left(\mathrm{t}, 2 \mathrm{H}, \mathrm{CH}_{2} \mathrm{~J}\right.$ = $6.7 \mathrm{~Hz}), 7.12\left(\mathrm{~m}, 2 \mathrm{H}, \mathrm{H}_{4^{\prime}, 6^{\prime}}\right), 7.30\left(\mathrm{~m}, 1 \mathrm{H}, \mathrm{H}_{5^{\prime}}\right), 7.96\left(\mathrm{~s}, 1 \mathrm{H}, \mathrm{H}_{4}\right) ;{ }^{13} \mathrm{C} \mathrm{NMR} \mathrm{CDCl}_{3} \delta$ ppm: 14.4, 39.0, 53.3, 53.7, 56.1, 58.2, 61.7, 116.6, 122.1, 124.3, 124.7, 133.6, 149.2, 151.2, 153.7, 165.5. Anal. calcd. for $\mathrm{C}_{17} \mathrm{H}_{21} \mathrm{~N}_{3} \mathrm{O}_{8} \mathrm{~S}$ : C, 47.77; H, 4.95; N, 9.83. Found: C, 47.78; H, 4.97; N, 10.05.

2-\{[2-(2-Methyl-5-nitro-1H-imidazol-1-yl)ethyl]sulfonyl\}ethyl 2,4-dimethoxybenzoate (10d)

Mp. $120-122{ }^{\circ} \mathrm{C}$; IR (Zn-Se) cm ${ }^{-1}: 2941,1711,1601,1458,1360 ;{ }^{1} \mathrm{H} \mathrm{NMR} \mathrm{CDCl}_{3} \delta$ ppm: 2.53 (s, 3H, $\mathrm{CH}_{3}$ ), 3.43 (t, $2 \mathrm{H}, \mathrm{CH}_{2} \mathrm{~J}=5.5 \mathrm{~Hz}$ ), 3.61 (t, $2 \mathrm{H}, \mathrm{CH}_{2} \mathrm{~J}=6.6 \mathrm{~Hz}$ ), $3.80\left(\mathrm{~s}, 3 \mathrm{H}, \mathrm{OCH}_{3}\right), 3.84\left(\mathrm{~s}, 3 \mathrm{H}, \mathrm{OCH}_{3}\right), 4.66\left(\mathrm{t}, 2 \mathrm{H}, \mathrm{CH}_{2} \mathrm{~J}=5.6 \mathrm{~Hz}\right), 4.75(\mathrm{t}, 2 \mathrm{H}$, $\left.\mathrm{CH}_{2} J=6.6 \mathrm{~Hz}\right), 6.44\left(\mathrm{~d}, 1 \mathrm{H}, \mathrm{H}_{3} J=2.3 \mathrm{~Hz}\right), 6.49\left(\mathrm{dd}, 1 \mathrm{H}, \mathrm{H}_{5}, J=8.8,2.3 \mathrm{~Hz}\right), 7.79$ $\left(\mathrm{d}, 1 \mathrm{H}, \mathrm{H}_{6}, J=8.7 \mathrm{~Hz}\right.$ ), 7.91 (s, $\left.1 \mathrm{H}, \mathrm{H}_{4}\right) ;{ }^{13} \mathrm{C} \mathrm{NMR} \mathrm{CDCl}_{3} \delta$ ppm: 14.4, 39.0, 53.2, 53.9, 55.7, 55.9, 57.6, 99.1, 105.1, 110.6, 133.7, 134.3, 151.3, 161.6, 164.8, 165.1. Anal. calcd. for $\mathrm{C}_{17} \mathrm{H}_{21} \mathrm{~N}_{3} \mathrm{O}_{8} \mathrm{~S}$ : C, 47.77; $\mathrm{H}, 4.95 ; \mathrm{N}, 9.83$. Found: $\mathrm{C}, 47.83 ; \mathrm{H}, 4.95$; N, 9.97.

2-\{[2-(2-Methyl-5-nitro-1H-imidazol-1-yl)ethyl]sulfonyl\}ethyl 2,5-dimethoxybenzoate (10e)

Mp. $137-139{ }^{\circ} \mathrm{C}$; IR (Zn-Se) cm ${ }^{-1}: 2933,1723,1533,1470,1364 ;{ }^{1} \mathrm{H} \mathrm{NMR} \mathrm{CDCl}{ }_{3} \delta$ ppm: 2.49 (s, 3H, $\mathrm{CH}_{3}$ ), 2.87 (t, $2 \mathrm{H}, \mathrm{CH}_{2} J=6.7 \mathrm{~Hz}$ ), 2.95 (t, $2 \mathrm{H}, \mathrm{CH}_{2} J=7.1 \mathrm{~Hz}$ ), $3.85\left(\mathrm{~s}, 3 \mathrm{H}, \mathrm{OCH}_{3}\right), 3.87\left(\mathrm{~s}, 3 \mathrm{H}, \mathrm{OCH}_{3}\right), 4.43\left(\mathrm{t}, 2 \mathrm{H}, \mathrm{CH}_{2} \mathrm{~J}=6.7 \mathrm{~Hz}\right), 4.46(\mathrm{t}, 2 \mathrm{H}$, $\left.\mathrm{CH}_{2} \mathrm{~J}=7.1 \mathrm{~Hz}\right), 7.05\left(\mathrm{~m}, 2 \mathrm{H}, \mathrm{H}_{4^{\prime}, 6^{\prime}}\right), 7.28\left(\mathrm{~m}, 1 \mathrm{H}, \mathrm{H}_{5^{\prime}}\right), 7.91\left(\mathrm{~s}, 1 \mathrm{H}, \mathrm{H}_{4}\right) ;{ }^{13} \mathrm{C} \mathrm{NMR}$ 
$\mathrm{CDCl}_{3} \delta$ ppm: $14.5,31.0,31.9,46.1,56.1,61.6,63.6,116.1,122.2,123.9,125.7$, 133.2, 149.2, 150.5, 153.61, 166.0. Anal. calcd. for $\mathrm{C}_{17} \mathrm{H}_{21} \mathrm{~N}_{3} \mathrm{O}_{8} \mathrm{~S}$ : C, 47.77; $\mathrm{H}$, 4.95; N, 9.83. Found: C, 47.79; H, 4.96; N, 10.01.

2-\{[2-(2-Methyl-5-nitro-1H-imidazol-1-yl)ethyl]sulfonyl\}ethyl

2,4,5-trimethoxybenzoate (10f)

Mp. $140-142{ }^{\circ} \mathrm{C}$; IR (Zn-Se) cm ${ }^{-1}: 2929,1715,1613,1511,1462,1356 ;{ }^{1} \mathrm{H}$ NMR $\mathrm{CDCl}_{3} \delta$ ppm: 2.56 (s, $\left.3 \mathrm{H}, \mathrm{CH}_{3}\right), 3.46\left(\mathrm{t}, 2 \mathrm{H}, \mathrm{CH}_{2} \mathrm{~J}=5.4 \mathrm{~Hz}\right), 3.65\left(\mathrm{t}, 2 \mathrm{H}, \mathrm{CH}_{2} \mathrm{~J}=\right.$ $6.5 \mathrm{~Hz}), 3.81\left(\mathrm{~s}, 3 \mathrm{H}, \mathrm{OCH}_{3}\right), 3.85\left(\mathrm{~s}, 3 \mathrm{H}, \mathrm{OCH}_{3}\right), 3.94\left(\mathrm{~s}, 3 \mathrm{H}, \mathrm{OCH}_{3}\right), 4.71(\mathrm{t}, 2 \mathrm{H}$, $\left.\mathrm{CH}_{2} \mathrm{~J}=5.6 \mathrm{~Hz}\right), 4.78\left(\mathrm{t}, 2 \mathrm{H}, \mathrm{CH}_{2} \mathrm{~J}=6.5 \mathrm{~Hz}\right), 6.49\left(\mathrm{~s}, 1 \mathrm{H}, \mathrm{H}_{3^{\prime}}\right), 7.39\left(\mathrm{~s}, 1 \mathrm{H}, \mathrm{H}_{6^{\prime}}\right)$, $7.93\left(\mathrm{~s}, 1 \mathrm{H}, \mathrm{H}_{4}\right) ;{ }^{13} \mathrm{C} \mathrm{NMR} \mathrm{CDCl}_{3} \delta \mathrm{ppm:} \mathrm{14.5,} \mathrm{39.1,} \mathrm{53.2,} \mathrm{53.9,} \mathrm{56.3,} \mathrm{56.6,} \mathrm{56.9,}$ $57.9,97.6,109.0,114.6,133.6,143.0,151.3,154.6,155.9,165.2$. Anal. calcd. for $\mathrm{C}_{18} \mathrm{H}_{23} \mathrm{~N}_{3} \mathrm{O}_{9} \mathrm{~S}: \mathrm{C}, 47.26 ; \mathrm{H}, 5.07 ; \mathrm{N}, 9.19$. Found: C, 47.30; $\mathrm{H}_{3} 5.12 ; \mathrm{N}, 9.41$.

2-\{[2-(2-Methyl-5-nitro-1H-imidazol-1-yl)ethyl]sulfonyl\}ethyl

3,4,5-trimethoxybenzoate (10g)

Mp. 147-149 ${ }^{\circ} \mathrm{C}$; IR (Zn-Se) $\mathrm{cm}^{-1}: 2923,1730,1711,1503,1449 ;{ }^{1} \mathrm{H} \mathrm{NMR} \mathrm{CDCl}_{3} \delta$ ppm: $2.58\left(\mathrm{~s}, 3 \mathrm{H}, \mathrm{CH}_{3}\right), 3.49\left(\mathrm{t}, 2 \mathrm{H}, \mathrm{CH}_{2} \mathrm{~J}=5.9 \mathrm{~Hz}\right), 3.58\left(\mathrm{t}, 2 \mathrm{H}, \mathrm{CH}_{2} \mathrm{~J}=6.6 \mathrm{~Hz}\right)$, $3.89\left(\mathrm{~s}, 6 \mathrm{H}, \mathrm{OCH}_{3}\right), 3.91\left(\mathrm{~s}, 3 \mathrm{H}, \mathrm{OCH}_{3}\right), 4.76\left(\mathrm{t}, 2 \mathrm{H}, \mathrm{CH}_{2} \mathrm{~J}=6.0 \mathrm{~Hz}\right), 4.78(\mathrm{t}, 2 \mathrm{H}$, $\left.\mathrm{CH}_{2} \mathrm{~J}=6.6 \mathrm{~Hz}\right), 7.25\left(\mathrm{~s}, 2 \mathrm{H}, \mathrm{H}_{2}, 6^{\prime}\right), 7.95\left(\mathrm{~s}, 1 \mathrm{H}, \mathrm{H}_{4}\right) ;{ }^{13} \mathrm{C} \mathrm{NMR} \mathrm{CDCl}_{3} \delta \mathrm{ppm}: 14.5$, 39.2, 53.1, 53.6, 56.4, 57.7, 61.0, 107.1, 123.8, 133.8, 143.0, 151.3, 153.2, 165.7. Anal. calcd. for $\mathrm{C}_{18} \mathrm{H}_{23} \mathrm{~N}_{3} \mathrm{O}_{9} \mathrm{~S}$ : C, 47.26; $\mathrm{H}, 5.07 ; \mathrm{N}, 9.19$. Found: C, 47.27; H, 5.09; N, 9.33.

2-\{[2-(2-Methyl-5-nitro-1H-imidazol-1-yl)ethyl]sulfonyl\}ethyl 4-methoxy-3-nitrobenzoate (10h)

Mp. $135-137{ }^{\circ} \mathrm{C}$; IR (Zn-Se) $\mathrm{cm}^{-1}: 2929,2365,1744,1711,1523,1458 ;{ }^{1} \mathrm{H}$ NMR $\mathrm{CDCl}_{3} \delta$ ppm: $2.60\left(\mathrm{~s}, 3 \mathrm{H}, \mathrm{CH}_{3}\right), 3.49\left(\mathrm{t}, 2 \mathrm{H}, \mathrm{CH}_{2} \mathrm{~J}=5.7 \mathrm{~Hz}\right), 3.59\left(\mathrm{t}, 2 \mathrm{H}, \mathrm{CH}_{2} \mathrm{~J}=\right.$ $6.7 \mathrm{~Hz}), 4.05\left(\mathrm{~s}, 3 \mathrm{H}, \mathrm{OCH}_{3}\right), 4.81\left(\mathrm{~m}, 4 \mathrm{H}, \mathrm{CH}_{2}\right), 7.17\left(\mathrm{~d}, 1 \mathrm{H}, \mathrm{H}_{5}, J=8.9 \mathrm{~Hz}\right), 7.97$ $\left(\mathrm{s}, 1 \mathrm{H}, \mathrm{H}_{4}\right), 8.17$ (dd, $\left.1 \mathrm{H}, \mathrm{H}_{6}, J=8.8,2.2 \mathrm{~Hz}\right), 8.47\left(\mathrm{~d}, 1 \mathrm{H}, \mathrm{H}_{2}, J=2.2 \mathrm{~Hz}\right) ;{ }^{13} \mathrm{C}$ NMR $\mathrm{CDCl}_{3} \delta$ ppm: 14.6, 39.2, 53.4, 57.1, 58.1, 113.7, 121.3, 127.6, 134.0, 135.5, 
151.4, 156.8. Anal. calcd. for $\mathrm{C}_{16} \mathrm{H}_{18} \mathrm{~N}_{4} \mathrm{O}_{9} \mathrm{~S}$ : C, 43.44; $\mathrm{H}, 4.10 ; \mathrm{N}, 12.66$. Found: $\mathrm{C}$, 43.48; H, 4.17; N, 12.81.

2-\{[2-(2-Methyl-5-nitro-1H-imidazol-1-yl)ethyl]sulfonyl\}ethyl 3,5-dimethylbenzoate (10i)

Mp. $105-107^{\circ} \mathrm{C}$; IR (Zn-Se) cm ${ }^{-1}: 2929,1703,1597,1458,1258 ;{ }^{1} \mathrm{H} \mathrm{NMR} \mathrm{CDCl}_{3} \delta$ ppm: 2.35 (s, $\left.6 \mathrm{H}, \mathrm{CH}_{3}\right), 2.58\left(\mathrm{~s}, 3 \mathrm{H}, \mathrm{CH}_{3}\right), 3.47$ (t, 2H, $\left.\mathrm{CH}_{2} \mathrm{~J}=5.8 \mathrm{~Hz}\right), 3.59$ (t, $2 \mathrm{H}$, $\mathrm{CH}_{2} J=6.6 \mathrm{~Hz}$ ), $4.75\left(\mathrm{t}, 2 \mathrm{H}, \mathrm{CH}_{2} \mathrm{~J}=5.8 \mathrm{~Hz}\right), 4.79\left(\mathrm{t}, 2 \mathrm{H}, \mathrm{CH}_{2} \mathrm{~J}=6.6 \mathrm{~Hz}\right), 7.22(\mathrm{~s}$, $\left.1 \mathrm{H}, \mathrm{H}_{4}\right), 7.58\left(\mathrm{~s}, 2 \mathrm{H}, \mathrm{H}_{2}, 6^{\prime}\right), 7.96\left(\mathrm{~s}, 1 \mathrm{H}, \mathrm{H}_{4}\right) ;{ }^{13} \mathrm{C} \mathrm{NMR} \mathrm{CDCl}_{3} \delta \mathrm{ppm:} \mathrm{14.5,} \mathrm{21.3,}$ $39.1,53.4,53.9,57.8,127.5,128.8,133.8,135.6,138.6$. Anal. calcd. for $\mathrm{C}_{17} \mathrm{H}_{21} \mathrm{~N}_{3} \mathrm{O}_{6} \mathrm{~S}$ : C, 51.64; H, 5.35; N, 10.63. Found: C, 51.67; H, 5.40; N, 10.89.

2-\{[2-(2-Methyl-5-nitro-1H-imidazol-1-yl)ethyl]sulfonyl\}ethyl

4-tert-butylbenzoate (10j)

Mp. 111-113 ${ }^{\circ} \mathrm{C}$; IR (Zn-Se) $\mathrm{cm}^{-1}: 2978,1711,1601,1523,1458 ;{ }^{1} \mathrm{H} \mathrm{NMR} \mathrm{CDCl}_{3} \delta$ ppm: 1.31 (s, 9H, t-Bu), $2.53\left(\mathrm{~s}, 3 \mathrm{H}, \mathrm{CH}_{3}\right), 3.46\left(\mathrm{t}, 2 \mathrm{H}, \mathrm{CH}_{2} J=5.8 \mathrm{~Hz}\right), 3.59(\mathrm{t}, 2 \mathrm{H}$, $\mathrm{CH}_{2} J=7.3 \mathrm{~Hz}$ ), $4.71\left(\mathrm{t}, 2 \mathrm{H}, \mathrm{CH}_{2} \mathrm{~J}=5.9 \mathrm{~Hz}\right), 4.76\left(\mathrm{t}, 2 \mathrm{H}, \mathrm{CH}_{2} \mathrm{~J}=6.7 \mathrm{~Hz}\right), 7.43(\mathrm{~d}$, $\left.2 \mathrm{H}, \mathrm{H}_{3^{\prime}, 5^{\prime}} \mathrm{J}=8.7 \mathrm{~Hz}\right), 7.86\left(\mathrm{~d}, 2 \mathrm{H}, \mathrm{H}_{2^{\prime}, 6} \mathrm{~J}=8.7 \mathrm{~Hz}\right), 7.89\left(\mathrm{~s}, 1 \mathrm{H}, \mathrm{H}_{4}\right) ;{ }^{13} \mathrm{C} N M R$ $\mathrm{CDCl}_{3} \delta$ ppm: $14.4,31.1,35.2,38.9,53.2,53.6,57.6,125.7,126.0,129.5,133.7$, 138.3, 151.3, 157.6, 165.8. Anal. calcd. for $\mathrm{C}_{19} \mathrm{H}_{25} \mathrm{~N}_{3} \mathrm{O}_{6} \mathrm{~S}$ : C, 53.89; $\mathrm{H}, 5.95 ; \mathrm{N}$, 9.92. Found: C, 53.92; H, 5.98; N, 10.19.

2-\{[2-(2-Methyl-5-nitro-1H-imidazol-1-yl)ethyl]sulfonyl\}ethyl

5-methyl-2-nitrobenzoate (10k)

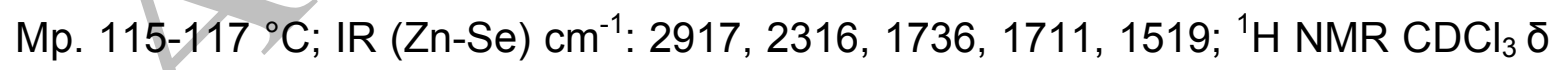
ppm: 2.48 (s, 3H, $\left.\mathrm{CH}_{3}\right), 2.56\left(\mathrm{~s}, 3 \mathrm{H}, \mathrm{CH}_{3}\right), 3.44\left(\mathrm{t}, 2 \mathrm{H}, \mathrm{CH}_{2} \mathrm{~J}=5.5 \mathrm{~Hz}\right), 3.49(\mathrm{t}, 2 \mathrm{H}$, $\left.\mathrm{CH}_{2} J=6.7 \mathrm{~Hz}\right), 4.75\left(\mathrm{~m}, 4 \mathrm{H}, \mathrm{CH}_{2}\right), 7.42\left(\mathrm{~m}, 1 \mathrm{H}, \mathrm{H}_{4^{\prime}}\right), 7.44\left(\mathrm{~s}, 1 \mathrm{H}, \mathrm{H}_{6^{\prime}}\right), 7.89(\mathrm{~d}, 1 \mathrm{H}$, $\mathrm{H}_{3}, J=9.1 \mathrm{~Hz}$ ), $7.92\left(\mathrm{~s}, 1 \mathrm{H}, \mathrm{H}_{4}\right) ;{ }^{13} \mathrm{C} \mathrm{NMR} \mathrm{CDCl}_{3} \delta \mathrm{ppm}: 14.4,21.5,39.0,53.0$, $59.0,124.5,127.3,130.1,132.5,133.7,145.1,145.7,151.3,165.5$. Anal. calcd. for $\mathrm{C}_{16} \mathrm{H}_{18} \mathrm{~N}_{4} \mathrm{O}_{8} \mathrm{~S}: \mathrm{C}, 45.07 ; \mathrm{H}, 4.26 ; \mathrm{N}, 13.14$. Found: C, 45.12; $\mathrm{H}, 4.32 ; \mathrm{N}, 13.40$. 
benzoate (10I)

Mp. $128-130{ }^{\circ} \mathrm{C}$; IR (Zn-Se) $\mathrm{cm}^{-1}: 2982,2361,1711,1531,1503,1454 ;{ }^{1} \mathrm{H}$ NMR $\mathrm{CDCl}_{3} \delta$ ppm: $2.58\left(\mathrm{~s}, 3 \mathrm{H}, \mathrm{CH}_{3}\right), 3.49$ (t, $\left.2 \mathrm{H}, \mathrm{CH}_{2} \mathrm{~J}=5.7 \mathrm{~Hz}\right), 3.59\left(\mathrm{t}, 2 \mathrm{H}, \mathrm{CH}_{2} J=\right.$ $6.6 \mathrm{~Hz}), 4.81\left(\mathrm{~m}, 2 \mathrm{H}, \mathrm{CH}_{2}\right), 7.73\left(\mathrm{~d}, 2 \mathrm{H}, \mathrm{H}_{3^{\prime}, 5}, J=8.8 \mathrm{~Hz}\right), 7.96\left(\mathrm{~s}, 1 \mathrm{H}, \mathrm{H}_{4}\right), 8.11(\mathrm{~d}$, $\left.2 \mathrm{H}, \mathrm{H}_{2^{\prime}, 6^{\prime}} \mathrm{J}=8.8 \mathrm{~Hz}\right) ;{ }^{19} \mathrm{~F} \mathrm{NMR}\left(\mathrm{CDCl}_{3}, 282 \mathrm{MHz}\right) \delta 63.20 ;{ }^{13} \mathrm{C} \mathrm{NMR} \mathrm{CDCl}_{3} \delta \mathrm{ppm}$ : $14.5,39.2,53.3,58.1,125.8,125.9,130.2,134.0,151.4,164.9$. Anal. calcd. for $\mathrm{C}_{16} \mathrm{H}_{16} \mathrm{~F}_{3} \mathrm{~N}_{3} \mathrm{O}_{6} \mathrm{~S}: \mathrm{C}, 44.14 ; \mathrm{H}, 3.70 ; \mathrm{N}, 9.65$. Found: C, 44.16; H, 3.75; N, 9.89.

\section{2 | Antileishmania assays}

\subsubsection{Culture and maintenance of parasite}

International reference strains of $L$. (V.) braziliensis (MHOM/BR/75/M2903) and $L$. (L.) mexicana (MHOM/BZ/82/Bel21) were thawed and cultured in RPMI 1640 medium (Gibco_BRL) at room temperature with $10 \%$ fetal bovine serum (FBS) inactivated by heating at $56{ }^{\circ} \mathrm{C}$ for 30 minutes. Finally, antibiotics (penicillin/streptomycin), at concentrations of 100 and 1000 units, respectively, were added. For the experiments, parasites were collected in the logarithmic phase of growth (fifth day of culture) by centrifugation at 3,000 rpm, washed three times with saline phosphate buffer, $\mathrm{pH}$ 8.0. The pellet was re-suspended in fresh medium and the parasites were adjusted to a concentration of $1 \times 10^{6} \mathrm{cells} / \mathrm{mL} .^{[32]}$

\subsubsection{Antileishmania activity on promastigote proliferation}

Each compound was diluted to a concentration of $50 \mathrm{mg} / \mathrm{mL}$ in appropriate solvent (DMSO) and, subsequently, dilutions between 10 and $500 \mu \mathrm{g} / \mathrm{mL}$ were prepared for the experiments. Different concentrations of each compound were used for the different species of Leishmania, i.e., L. (V.) braziliensis or L. (L.) mexicana, to investigate the response of the parasite to each compound. A daily sample of $5 \mu \mathrm{L}$ was taken for cell counting. The count was performed in triplicate for 7 days, until the culture reaches the stationary phase of growth. The effect of each compound over the different Leishmania species was evaluated. ${ }^{[32]}$ 


\subsection{3 | Calculation of cell viability and $\mathrm{LC}_{50}$}

To evaluate the effect of the compounds on cell viability and in order to calculate the $\mathrm{LC}_{50}$, two methods were used:

\subsubsection{1 | Indirect method}

Parasites were incubated with various concentrations of the respective compound for 18-24 hours; thereafter, $10 \mu \mathrm{L}(10 \mathrm{mg} / \mathrm{mL})$ of methyl-thiazole tetrazolium (MTT, Sigma) were added and incubated for 4 hours. After incubation, the reaction was stopped with lysis buffer (50\% isopropyl alcohol, 10\% SDS), and then the optical density (OD) was measured at $570 \mathrm{~nm}$ in a spectrophotometer (Biorad). Cell viability is directly proportional to $O D$, since the higher number of living cells has greater color intensity, because they have high capacity to metabolize the MTT. For each experiment, different controls were used; including cells treated with solvent only, controls without and with meglumine antimoniate (i.e., drug of choice in the treatment of leishmaniasis). The effect of each compound on the growth of the parasites in relation to controls was used to estimate the concentration that causes the death of $50 \%$ of the cells in a given time $\left(\mathrm{LC}_{50}\right)$.

\subsubsection{2 | Direct method}

This method is based on the comparison between two doses that we call $X_{1}$ and $X_{2}$, such that the density of parasites $\left(Y_{1}\right)$ to the $X$ dose 1 is greater than half of the density found in the control (I); and the density of parasites $Y_{2}$ found to the dose $X_{2}$ is less than half of the control. Then we can calculate the lethal concentration 50 (LC $\left.{ }_{50}\right)$ using the algorithm previously described by Huber and Koella. ${ }^{[33]}$ For promastigote, $1 \times 10^{6}$ parasites were added in $2 \mathrm{~mL}$ of medium SDM 79 at $\mathrm{pH} 7.2$ supplemented with $10 \%$ fetal serum and $100 \mu \mathrm{L}$ of penicillin-streptomycin in sterile 6 wells plates and treated with different concentrations of the compound, then incubated at $26{ }^{\circ} \mathrm{C} .5 \mu \mathrm{L}$ of each sample was taken daily, by triplicate and the respective controls. Viability was determined by counting the cells stained with trypan blue. 


\section{ACKNOWLEDGMENTS}

We thank the Instituto de Investigaciones Farmacéuticas (IIF) and Consejo de Desarrollo Científico y Humanístico de la Universidad Central de Venezuela (CDCH-UCV) (grants IIF.01-2014, PG. 09-8819-2013/2), and the FranceVenezuela PCP program No. 2013000438, as well as the University of Bordeaux, the Ministère de l'Enseignement Supérieur, de la Recherche et de l'Innovation and the Centre National de la Recherche Scientifique (CNRS) for financial support. This work has benefited from the analytical facilities and expertise of the CESAMO platform at the University of Bordeaux, and of the CNRS-UMS 3033 at the European Institute of Chemistry and Biology.

\section{Supplementary data}

Supplementary data of NMR spectra $\left({ }^{1} \mathrm{H}\right.$ and ${ }^{13} \mathrm{C}$ NMR) for all compounds described are available.

\section{CONFLICT OF INTERESTS}

The authors declare that there are no conflict of interests.

\section{ORCID}

Stéphane Quideau http://orcid.org/0000-0002-7079-9757 Laurent Pouységu http://orcid.org/0000-0002-4310-848X Jaime Charris http://orcid.org/0000-0003-4404-2619

\section{REFERENCES}

[1] https://www.who.int/en/news-room/factsheets/detail/leishmaniasis. (2019 Accessed 07-07-2019).

[2] K. Singh, G. Garg, V. Ali, Curr. Drug Metab. 2016, 17, 897.

[3] J. Sangshetti, F. Kalam, A. Kulkarni, A. Rohidas, R. Patilc, RSC Adv., 2015, 5, 32376.

[4] R. Dietze, S. Carvalho, L. Valli, J. Berman, T. Brewer, W. Milhous, J. Sanchez, B. Schuster, M. Grogl, Am. J. Trop. Med. Hyg. 2001, 65, 685.

[5] P. Loiseau, S. Cojean, J. Schrével, Parasite 2011, 18, 115. 
[6] J. Seeberger, S. Daoud, J. Pammer, Intl. J. Dermatol. 2003, 42, 576.

[7] H. Al-Abdely, J. Graybill, D. Loebenberg, P. Melby, Antimicrob. Agents Chemother. 1999, 43, 2910.

[8] E. de Morais-Teixeira, A. Rabello, M. G. Aguiar, J. Antimicrob. Chemother. 2019, 74, 2318.

[9] L. Zhai, M. Chen, J. Blom, T. Theander, S. Christensen, A. Kharazmi, J. Antimicrob. Chemother. 1999, 43, 793.

[10] T. Stefanello, M. Panice, T. Ueda-Nakamura, M. Sarragiotto, R. AuzélyVelty, C. Nakamura, Antimicrob. Agents Chemother. 2014, 58, 7112.

[11] I. Singh, S. Jain, A. Kaur, S. Singh, R. Kumar, P. Garg, S. Sharma, S. Arora, Eur. J. Med. Chem. 2010, 45, 3439.

[12] A. Tiwari, S. Kumar, R. Shivahare, P. Kant, S. Gupta, S. Suryawanshi, Bioorg. Med. Chem. Lett. 2015, 25, 410.

[13] V. Gómez-Pérez, J. Manzano, R. García-Hernández, S. Castanys, F. Gamarro, J. Campos, Eur. J. Med. Chem. 2015, 89, 362.

[14] D. Truong, Clin. Interv. Aging 2009, 4, 109.

[15] E. Sorkin, S. Clissold, R. Brogden, Drugs 1985, 30, 182.

[16] M. Mattila, H. Larni, Drugs 1980, 20, 353.

[17] W. Raether, H. Hänel, Parasitol. Res. 2003, 90, S19.

[18] S. Wilkinson, C. Bot, J. Kelly, B. Hall. Curr. Top. Med. Chem. 2011, 11, 2072.

[19] A. Salahuddin, S. Agarwal, F. Avecilla, A. Azam, Bioorg. Med. Chem. Lett. 2012, 22, 5694.

[20] P. Bano, S. Shahab, J. Assoc. Physic. India 1994, 42, 535.

[21] M. Al-Waiz, K. Sharquie, M. Al-Assir, Saudi Med. J. 2004, 25, 1512.

[22] S. Bahashwan, Trop. J. Pharma. Res. 2011, 10, 255.

[23] M. Mishra, B. Thakur, M. Choudhary, British Med. J. 1985, 291, 1611.

[24] S. Patterson, S. Wyllie, Trends Parasitol. 2014, 30, 289.

[25] A. S. Surur, L. Schulig, A. Link, Arch. Pharm. Chem. Life Sci. 2019, 352, e1800248. 
[26] J. Rodrigues, J. Charris, R. Ferrer, N. Gamboa, J. Ángel, B. Nitzche, M. Hoepfner, M. Lein, K. Jung, C. Abamjuk, Invest. New Drugs 2012, 30, 1426.

[27] L. Kumar, A. Sarswat, N. Lal, V. Sharma, A. Jain, R. Kumar, V. Verma, J. Maikhuri, A. Kumar, P. Shukla, G. Gupta, Eur. J. Med. Chem. 2010, 45, 817.

[28] L. Kumar, A. Jain, N. Lal, A. Sarswat, S. Jangir, L. Kumar, V. Singh, P. Shah, S. Jain, J. Maikhuri, M. Siddiqi, G. Gupta, V. Sharma, Med. Chem. Lett. 2012, 3, 83.

[29] G. Malik, A. Natangelo, J. Charris, L. Pouységu, S. Manfredini, D. Cavagnat, T. Buffeteau, D. Deffieux, S. Quideau, Chem. Eur. J. 2012, 18, 9063.

[30] T. Gantchev, D. Hunting, Biochem. Biophys. Res. Commun. 1997, 237, 24.

[31] S. Quideau, D. Deffieux, C. Douat-Casassus, L. Pouységu, Angew. Chem. Int. Ed. 2011, 50, 586.

[32] S. Brito, O. Crescente, A. Fernández, A. Coronado, N. Rodríguez, Biomedica 2006, 26, 180.

[33] W. Huber, J. Koella, Acta Trop. 1993, 55, 257. 